\title{
Racionalidad ambiental y diálogo de saberes: sentidos y senderos de un futuro sustentable
}

\section{Environmental Rationality and dialogue of know ledge senses and meaning of a sustainable future}

\author{
Enrique LEFF*
}

Soy tú cuando soy yo

Paul Celan

\begin{abstract}
RESUMO
O texto parte da problematização de algumas categorias de análise, tais como as de "racionalidade comunicativa" (Habermas) e de "alteridade", de "infinito"e de "totalidade"(Lévinas), para contrastar os conceitos de "racionalidade ambiental", "saber ambiental" e "diálogo de saberes". A racionalidade ambiental encontra sua morada no saber ambiental. Este, por sua vez, não pode confinar-se nos conhecimentos científicos constituídos. O diálogo de saberes se inscreve em uma política da diferença, a qual ultrapassa o pensamento ecologista e o sistema dos saberes existentes, constituindo-se no encontro com a alteridade. A construção da racionalidade ambiental conduz à desconstrução das lógicas de conhecimento e de poder dominantes, abrindo as vias para outras ressignificações da natureza por meio da linguagem e das novas estratégias de apropriação da natureza desde a cultura. Palavras-chave: racionalidade ambiental, diálogo de poderes, alteridade.
\end{abstract}

\section{RESUMEN}

El texto parte de la problematización de algunas categorias de análisis, tales como de "racionalidad comunicativa" (Habermas) y de "otredad", "inifinito" y “totalidad" (Lévinas), para contrastar los conceptos de "racionalidad ambiental", "saber ambiental" y "diálogo de saberes". La racionalidad ambiental se construye en el contexto del saber ambiental, el cual no se restringe a los conocimientos científicos constituidos. El diálogo de saberes se inscribe en una política de la diferencia que desborda al pensamiento ecologista y al sistema de los saberes existentes, constituyéndose en el encuentro con la otredad. La construcción de una racionalidad ambiental conduce a la desconstrucción de los sistemas de conocimiento y de poder dominantes, abriendo posibilidades para otras resignificaciones de la naturaleza a través del lenguaje, y nuevas estrategias de apropiación de la naturaleza desde la cultura.

Palabras-clave: racionalidad ambiental, diálogo de saberes, otredad.

\footnotetext{
* Coordenador da Rede de Formação Ambiental da América Latina e Caribe, do PNUD; professor da Unam do México; professor visitante do Curso de Doutorado em Meio Ambiente e Desenvolvimento da Universidade Federal do Paraná.
} 


\begin{abstract}
This article takes a critical stand on the analytical categories of "communicative rationality" (Habermas) and "otherness", "infinity", and "totality" (Lévinas), and puts them in contrast with the concepts of "enviromnental rationality", "environmental knowledge" and "dialogue of knowledges". Environmental rationality is constructed la the context of environmental knowledge, which is not restricted to scientific knowing. The knowledge dialog is based on a politics of difference, which supersedes ecological thought and any established system of knowledge. It rather emerges in its encounter with otherness. The construction of an environmental rationality leads to the deconstruction of the dominant systems of power and knowledge, opening new possibilities for other meanings of nature in the realm of language, and of new strategies for the appropriateness of nature through culture.

Key-words: environmental rationality, dialogue of knowledges, otherness.
\end{abstract}

\section{Introducción}

La crisis ambiental es el síntoma -la marca en el ser, en el saber, en la tierra- del límite de la racionalidad fundada en una creencia insustentable: la del entendimiento y construcción del mundo llevado por la idea de totalidad, universalidad y objetividad del conocimiento que condujo a la cosificación y economización del mundo.

El ecologismo es el último intento por recuperar la unidad de ese mundo resquebrajado, fundado en ese mito de origen anclado en la metafísica, que, con la disyunción entre el ser y el ente, inicia la odisea del mundo occidental, aventura civilizatoria que llega a su límite con la crisis ambiental: crisis de la naturaleza en tanto que degradación del ambiente, pero sobre todo, crisis del conocimiento que sólo es posible trascender rompiendo el cerco de la mismidad del conocimiento y su identidad con lo real fundado en el imaginario de la representación, abriéndose al infinito desde un diálogo de saberes en el encuentro del Ser con la Otredad.

A partir de los años sesenta, la interdisciplinariedad y las teorías de sistemas aparecieron como las vías más certeras para articular un conocimiento fraccionado del mundo (LEF, 2001a). Al mismo tiempo se fue configurando un discurso en torno al desarrollo sostenible, el cual busca actualizar y unificar las visiones del mundo conmovidas y dislocadas por la crisis del desarrollo y el límite del crecimiento económico. En la perspectiva de la sustentabilidad, reemerge la idea de futuro -de un futuro sustentable- en el campo de la historia, de un proceso de transformación social orientado por una ética de solidaridad transgeneracional.

El discurso del desarrollo sostenible se ha dado unos principios que deberían orientar las acciones para alcanzar los fines de la sustentabilidad. Así llega a formularse la idea de un "futuro común" como el "saber de fondo" en el que se inscriben los Principios de Río, la Carta de la Tierra, la Agenda 21 y el más reciente Plan de Implementación de Johannesburgo. Los documentos en los que se plasma este ideario -con problemas a resolver, mecanismos a establecer y fines a alcanzar-, confor-man una bitácora programática de acciones a emprender, de políticas a desarrollar, de comportamientos a modificar. Mas estos principios no alcanzan a constituir una ética, una deontología, una racionalidad práctica o una ruta crítica para alcanzar fines de sustentabilidad.

La sustentabilidad, como marca de un límite de la racionalidad que organiza al planeta-mundo y a los mundos de vida en la era de la globalización, es el horizonte que permite trascender el cierre de la historia y reabrir el caso del punto final del estado del mundo que, partiendo de la denominación de lo real, llega al congelamiento de sus significados; no tanto por un agotamiento de la significancia del lenguaje, sino por la codificación del mundo bajo el signo omnipresente, omnipotente y ominoso de la ley económica. La "logística" del desarrollo sostenible se viene aplicando como un ars combinatoria, en un intento de reintegrar las partes disociadas y fragmentadas del todo social, sin un fundamento teórico sobre las raíces ontológica, epistemológica y ética de esta crisis de la humanidad. La construcción de un futuro sustentable implica pensar la apertura de la historia, el desujetamiento del orden cosificador y sobreeconomi-zador del mundo. Apunta hacia la creatividad humana, el cambio social y la construcción de alternativas. Es ello lo que lleva a pensar la apertura de lo mismo hacia lo otro.

En la profundidad de las transformaciones y en el reordenamiento del mundo bajo la égida de la globali-zación 
económico-ecológica, está fraguando el campo de una ecología política, donde emergen los conflictos en torno a la apropiación social de la naturaleza. Estos procesos se expresan en formaciones discursivas que resignifican a la naturaleza y confrontan a las políticas dominantes del desarrollo sostenible. La disputa sobre los sentidos de la sustentabilidad dentro del campo de la ecología política problematiza los principios éticos, epistemológicos y ontológicos, atrayéndolos de su campo originario de la metafísica y de la filosofía, al del conflicto de intereses en torno a la apropiación social de la naturaleza (LEFF, 2003b). Es en este sentido se abren nuevas perspectivas de indagación sobre los procesos sociales que orientan la construcción de un futuro sustentable:

1) el desbordamiento de la interdisciplinariedad como una combinatoria e integración de las perspectivas provenientes de las disciplinas existentes y sus referentes (cosificados) del mundo, hacia el diálogo de saberes. Ello implica que la compresión y la intervención social sobre la naturaleza rebasan el campo privilegiado de las ciencias y de la racionalidad dominante para pensar la sustentabilidad desde el encuentro de seres constituidos por saberes;

2) la construcción de una racionalidad ambiental dentro de un campo conflictivo de intereses y concepciones diversos, que pone en juego una disputa sobre los sentidos de la sustentabilidad, problematizando el lugar del conocimiento, de la racionalidad, del saber y de la ética en la construcción de un futuro sustentable;

3) el pensar y construir sociedades sustentables trascendiendo la relación del conocimiento con la objetividad de una realidad producida por el efecto de las formas de comprensión del mundo, abriendo la puerta de la historia desde la relación ética del Ser con lo Otro.

Estos temas ponen de relieve el problema de la relación social a través del lenguaje y del habla, de la comunicación intersubjetiva y de la relación de otredad, que llevan a cuestionar y a desconstruir los preconceptos que fundan nuestra percepción del mundo desde las entrañas de su racionalidad dominante. Para ello habremos de explorar dos vías para abordar el encuentro de saberes y de racionalidades en la construcción del desarrollo sostenible:

1) el concepto de racionalidad comunicativa de Jurgen Habermas, como forma de entendimiento de los procesos actuales de racionalización social, en cuanto a su posibilidad de conducir hacia la construcción de un consenso social que oriente la acción social para alcanzar un futuro común sustentable;

2) el concepto de otredad de Emmanuel Lévinas, que introduce una relación ética, anterior y más allá de toda ontología y toda epistemología, en la construcción de un porvenir sustentable.

Estas vías serán contrastadas con el concepto de racionalidad ambiental y nos llevarán a desarrollar los principios de un diálogo de saberes en la construcción de sociedades sustentables. Esta indagación habrá de problematizar el concepto mismo del saber (ambiental) para pensar las relaciones de constitución entre el ser y el saber que permita trascender las relaciones de conocimiento del mundo entre sujeto cognoscente y realidad objetiva; de los límites de lo cognoscible y la apertura a lo Otro y lo Infinito desde la perspectiva ética. La racionalidad ambiental emergerá como el concepto de una razón razonable que trasciende a la racionalidad sujeta a la positividad de un presente sin futuro, de una utilidad sin valores, de un mundo economizado sin sentidos.

El diálogo de saberes es la tensión dialéctica del vacío de sentido, de lo que falta por decir al poner en tensión dos palabras, dos sentencias, dos propuestas, dos razones, dos argumentaciones. Este texto es el diálogo de saberes entre la racionalidad comunicativa de Habermas y la epifanía del rostro de Lévinas, de donde emerge la potencia de la razón, de la palabra, del habla y de lo inefable en el encuentro con la otredad más allá de la razón teórica y la ontología del ser. En este sentido, este texto es una puesta en acto (de escritura) de un diálogo en el que la relación de otredad de los saberes convocados se produce en un texto a texto (letra a letra), más acá del encuentro cara a cara y el diálogo fresco de la palabra viva de los actores sociales, quienes desde sus razones, significaciones y prácticas, apuestan por un futuro sustentable. 


\section{Habermas y la racionalidad comunicativa}

Jurgen Habermas se inscribe dentro de la tradición del pensamiento crítico alemán que, de Marx y Weber a Horkheimer y Adorno, cuestionan el saber totalizante que se desprende de la racionalidad teórica e instrumental como fundamento del pensamiento de la modernidad. Sin abandonar dicho concepto de racionalidad, busca actualizarlo y adecuarlo al carácter de la sociedad que esta misma racionalidad ha construido. De esta manera postula que,

...la teoría de la acción comunicativa puede explicar (el hecho de que) es la propia evolución social la que tiene que generar los problemas que objetivamente abran a los contemporáneos un acceso privilegiado a las estructuras generales de su mundo de vida. (HABERMAS, 1990, p. 572)

Y en esta perspectiva declara,

...el propósito de este bosquejo argumentativo es mostrar que necesitamos de una teoría de la acción comunicativa si queremos abordar hoy de forma adecuada la problemática de la racionalización social. (HABERMAS, 1989, p. 23)

Habermas recusa la totalización del conocimiento. De esta manera señala que

...la filosofía no puede referirse hoy al conjunto del mundo, de la naturaleza, de la historia y de la sociedad, en el sentido de un saber totalizante (...) El caso es que el pensamiento, al abandonar su referencia a la totalidad, pierde también su autarquía. Pues el objetivo que ahora ese pensamiento se propone de un análisis formal de las condiciones de racionalidad no permite abrigar ni esperanzas ontológicas de conseguir teorías substantivas de la naturaleza, la historia, la sociedad, etc., ni tampoco las esperanzas que abrigó la filosofía trascendental de una reconstitución apriorística de la dotación trascendental de un sujeto genérico, no empírico, de una conciencia en general. (HABERMAS, 1989 p. 16-17)

Claramente estamos en un más allá de los intentos de retotalización del conocimiento por la vía de la razón teórica, el pensamiento sistémico y la interdisciplinariedad de las ciencias. Sin embargo, este esfuerzo de "desconstrucción" del saber totalizante, de la esencialidad ontológica que soporta las teorías objeti-vantes y de una conciencia general fundada en la idea de un sujeto trascendental, traslada la supremacía del concepto científico y la categoría filosófica que sostienen a la racionalidad teórica e instrumental, una razón inmanente al uso del lenguaje como soporte a su racio-nalidad comunicativa. En este sentido, Habermas busca:

...introducir una teoría de la acción comunicativa que dé razón de los fundamentos normativos de una teoría crítica de la sociedad (...) dentro del cual puede retomarse aquel proyecto de estudios interdisciplinarios sobre el tipo selectivo de racionalización que representa la modernización capitalista (...) (a partir) del concepto de razón comunicativa, de una razón inmanente al uso del lenguaje, cuando este uso se endereza al entendimiento. (1990, p. 563)

Con su teoría de la acción comunicativa, Habermas busca ver cómo "esta razón objetivamente escindida en sus momentos puede mantener todavía una unidad y (...) cómo establecer una mediación entre las culturas de expertos y la práctica cotidiana." (HABERMAS, 1989, p. 564) Ante la recusa de un saber totalizador, la racionalidad comunicativa enfrenta el reto de hacer inteligible la dispersión de enunciados y actos de habla. Basado en una teoría de la argumentación, Habermas busca una fórmula razonable para alcanzar consensos a través de una comunicación que es expresa a través del lenguaje racional, superando las sombras de irracionalidad que refleja el fracaso del iluminismo ante la imposible transparencia del mundo.

Siguiendo la tradición filosófica del idealismo, el racionalismo y la fenomenología, Habermas continúa adherido a una suerte de razón "a priori" -unitaria, universal, genérica-inmanente al lenguaje, capaz de generar consensos entre racionalidades y mundos de vida diferentes. En esta perspectiva, afirma que

...el mundo sólo cobra objetividad por el hecho de ser reconocido y considerado como uno y el mismo mundo por una comunidad de sujetos capaces de lenguaje y de acción. El concepto abstracto de mundo es condición necesaria para que los sujetos que actúan comunicativamente puedan entenderse entre sí sobre lo que sucede en el mundo o lo que hay que producir en el mundo. 
Con esta práctica comunicativa se aseguran a la vez del contexto común de sus vidas, del mundo de la vida que intersubjetivamente comparten. Este viene delimitado por la totalidad de las interpretaciones que son presupuestas por los participantes como un saber de fondo. Para poder aclarar el concepto de racionalidad, el fenomenólogo tiene que estudiar, pues, las condiciones que han de cumplirse para que se pueda alcanzar comunicativamente el consenso. (1989, p. 30-31)

Veremos más adelante cuan alejado de este mundo ideal de una intersubjetividad basada en un "saber de fondo" está la visión de una racionalidad ambiental conformada por matrices de racionalidad que no unifican sus visiones, cogniciones e interpretaciones en ninguna totalidad, y cuyos consensos no disuelven las diferencias que alimentan la productividad del diálogo de los saberes que en ellas se inscriben. En todo caso, el saber de fondo que establece las condiciones de consenso no sólo deriva de una racionalidad instrumental o a una pretensión de verdad preestablecida. Pues, como afirma Habermas,

...la racionalidad de las personas no sólo se manifiesta en su capacidad para llegar a un acuerdo sobre hechos o para actuar con eficiencia (...) es evidente que existen otros tipos de emisiones y manifestaciones que, aunque no vayan vinculadas a pretensiones de verdad o de eficiencia, no por ello dejan de contar con el respaldo de buenas razones.

Habermas incorpora así dentro del campo de lo racional a toda acción que, fundándose en valores, sea capaz de ser argumentada racionalmente y susceptible de crítica. En este sentido, llama también racional

...a aquel que sigue una norma vigente y es capaz de justificar su acción frente a un crítico interpretando una situación dada a la luz de expectativas legítimas de comportamiento. E incluso llamamos racional a aquel que expresa verazmente un deseo, un sentimiento, un estado de ánimo, que revela un secreto, que confiesa un hecho, etc., y que después convence a un crítico de la autenticidad de la vivencia así develada sacando las consecuencias prácticas y comportándose en forma consistente con lo dicho (incluyendo las) manifestaciones provistas de sentido inteligibles en su contexto, que van vinculadas a una pretensión de validez susceptible de crítica. (HABERMAS, 1989, p. 34)
De esta manera, una acción no es racional por ser estrictamente objetiva y corresponder con "hechos", sino por ser argumentable racionalmente y susceptible de crítica. En este sentido, la racionalidad comunicativa excluye las razones inefables y las motivaciones irracionales, considerando válidas tan sólo las expresiones que puedan establecer una intersubjetividad fundada en un código cultural y estándares de valor compartidos, de manera que

\begin{abstract}
...las acciones reguladas por normas, las autopresentaciones expresivas y las manifestaciones o emisiones evaluativos vienen a completar los actos de habla constatativos para configurar una práctica comunicativa que sobre el trasfondo de un mundo de vida tiende a la consecución, mantenimiento, y renovación de un consenso que descansa sobre el reconocimiento intersubjetivo de pretensiones de validez susceptibles de crítica. (HABERMAS, 1989, p. 36)
\end{abstract}

En este sentido, los valores son válidos en la medida que remitan a juicios objetivos que se expresan a través de una capacidad argumentativa sobre un saber de fondo, delimitando el campo de la racionalidad a aquél en el cual un hecho o un valor sean fundamentables objetivamente y susceptibles de crítica. Y en este sentido considera que

...una manifestación cumple los presupuestos de la racionalidad si y sólo si encarna un saber falible guardando así una relación con el mundo objetivo, esto es, con los hechos, y resultando accesible a un enjuiciamiento objetivo. (HABERMAS, 1989, p. 26).

\section{Habermas parte de}

...la versión cognitiva en sentido estricto del concepto de racionalidad, que está definido exclusivamente por referencia a la utilización de un saber descriptivo (...) de la utilización no comunicativa de un saber proposicional en acciones teleológicas (que nace) del concepto de racionalidad cognitivo-instrumental que a través del empirismo ha dejado una profunda impronta en la autocomprensión de la modernidad. Este concepto tiene la connotación de una autoafirmación con éxito en el mundo objetivo posibilitada por la capacidad de manipular informadamente y de adaptarse inteligentemente a las condiciones de un entorno contingente. (A esta versión cognitiva Habermas añade) la utilización comunicativa 
del saber proposicional en actos de habla (incorporando) un concepto de racionalidad más amplio que enlaza con la vieja idea de logos. Este concepto de racionalidad comunicativa posee connotaciones que en última instancia se remontan a la experiencia central de la capacidad de aunar sin coacciones y de generar consenso que tiene un habla argumentativa en que diversos participantes superan la subjetividad inicial de sus respectivos puntos de vista y merced a una comunidad de convicciones racionalmente motivada se aseguran a la vez de la unidad del mundo objetivo y de la intersubjetividad del contexto en que desarrollan sus actividades. (HABERMAS, 1989, p. 27)

La racionalidad comunicativa se enmarca así en una concepción del mundo objetivo y de una intersub-jetividad anclada en un yo dueño de su lenguaje y de su razón. Sin embargo, la capacidad argumentativa no remite ni a la verdad ni a la justicia. Habermas no logra despren-derse de la idea de racionalidad que organiza y limita el entendimiento del mundo moderno. De esta manera, concibe al psicoanálisis como una terapéutica basada en la argumentación, donde en el "proceso de autorre-flexión juegan su papel las razones; el correspondiente tipo de argumentación lo estudió Freud para el caso del diálogo terapéutico entre el médico y el paciente." Los sueños, los deseos, las utopías, la denegación y la resistencia del silencio -todo lo que estaría estructurado por el lenguaje del deseo inconsciente- estarían fuera de la esfera de la racionalidad comunicativa, pues lo racional sería exclusivo de "una persona que se muestra dispuesta al entendimiento y que ante las perturbaciones de la comunicación reacciona reflexionando sobre las reglas lingüísticas." (HABERMAS, 1989, p. 42)

Siguiendo a Horkheimer y Adorno, Habermas busca superar el entendimiento del mundo desde el principio de representación y de la racionalidad cognitivo-instrumental para construir el concepto de racionalidad comunicativa fundado en una filosofía del lenguaje en el que:

...esa facultad mimética (que) escapa a la conceptualización de las relaciones sujeto-objeto definidas en términos cognitivo-instrumentales (donde) el núcleo racional de estas operaciones miméticas sólo podría quedar al descubierto si se abandona el paradigma de un sujeto que se representa los objetos y que se forma en el enfrentamiento con ellos por medio de la acción, se lo sustituye por el paradigma de la filosofía del lenguaje, (donde) el entendimiento intersubjetivo o comunicación, y el aspecto cognitivo-instrumental queda inserto en el concepto, más amplio, de racionalidad comunicativa. (Ello implica) un cambio de paradigma en teoría de la acción: mudar de la acción teleológica a la acción comunicativa; y por otro, un cambio de estrategia en la tentativa de reconstruir el concepto moderno de racionalidad que la descentración de la comprensión del mundo hace posible. El fenómeno que hay que explicar ya no es el conocimiento y el sojuzgamiento de una naturaleza objetivada tomados en sí mismos, sino la intersubjetividad del entendimiento posible (...) El foco de la investigación se desplaza entonces de la racionalidad cognitivo-instrumental a la racionalidad comunicativa. (1989, p, 497, 499)

Habermas deja atrás el paradigma del conocimiento de lo real fundado en el imaginario de la representación para acercarse a un entendimiento del mundo. De esta manera busca pasar de la filosofía de la conciencia a una filosofía del lenguaje que daría nuevas bases a la idea iluminista de la razón y los procesos de racionalización, en el sentido de repensar las condiciones de un pacto social orientado por un entendimiento del mundo y fundado en una racionalidad comunicativa:

...a diferencia de "representación" o de "conocimiento",
"entendimiento" precisa de la apostilla "no coaccionado",
ya que ese término ha de entenderse aquí en el sentido de
un concepto normativo. Desde la perspectiva de los par-
ticipantes, "entendimiento" no significa un proceso
empírico que da lugar a un consenso fáctico, sino un
proceso de recíproco convencimiento, que coordina las
acciones de los distintos participantes a base de una
motivación por razones (...) Es precisamente esto lo que
nos autoriza a abrigar la esperanza de obtener, a través de
la clarificación de las propiedades formales de la
interacción orientada al entendimiento, un concepto de
racionalidad que exprese la relación que entre sí guardan
los momentos de la razón separados en la modernidad,
ya los rastreemos en las esferas culturales del valor, en
las formas diferenciadas de argumentación o en la propia
práctica comunicativa cotidiana. (HABERMAs, 1989, p. 500)

Empero, la razón integradora, conciliadora y consensual que propone Habermas resulta en una racionalización de lo social establecido y del pensamiento de lo social por el funcionamiento de la racionalidad inmanente a la acción comunicativa. La racionalidad comunicativa sería la que correspondería al estado de lo social (al estado democrático) en la modernidad: 
...si partimos de que la especie humana se mantiene a través de las actividades socialmente coordinadas de sus miembros y de que esta coordinación tiene que establecerse por medio de la comunicación, y en los ámbitos centrales por medio de una comunicación tendente a un acuerdo, entonces la reproducción de la especie exige también el cumplimiento de las condiciones de la racionalidad inmanente a la acción comunicativa. Estas condiciones se tornan accesibles en la modernidad -es decir, con la descentración de la comprensión del mundo y la diferenciación de distintos aspectos universales de validez (...) El proceso de autoconservación, al tener ahora que satisfacer las condiciones de racionalidad de la acción comunicativa, pasa a depender de las operaciones interpretativas de los sujetos que coordinan su acción a través de pretensiones de validez susceptibles de crítica. De allí que lo característico de la posición de la conciencia moderna no sea tanto la unidad de autoconservación y autoconciencia como esa situación de que son expresión la filosofía social burguesa y la filosofía burguesa de la historia: que el plexo de la vida social se reproduce a través de las acciones "racionales con arreglo a fines" de sus miembros, controlados por medios generalizados de comunicación, y simultáneamente a través de una voluntad común anclada en la práctica comunicativa de todos los individuos (...) A diferencia de la razón instrumental, la razón comunicativa no puede subsumirse sin resistencias bajo una autoconservación enceguecida. Se refiere no a un sujeto que se conserva relacionándose con objetos en su actividad representativa y en su acción, no a un sistema que mantiene su consistencia o patrimonio deslindándose frente a un entorno, sino a un mundo de la vida simbólicamente estructurado que se constituye en las aportaciones interpretativas de los que a él pertenecen y que sólo se reproduce a través de la acción comunicativa. Así, la razón comunicativa no se limita a dar por supuesta la consistencia de un sujeto o de un sistema, sino que participa en la estructuración de aquello que se ha de conservar. La perspectiva utópica de reconciliación y libertad está basada en las condiciones mismas de la socialización (Vergesellschaftung) comunicativa de los individuos, está ya inserta en el mecanismo lingüístico de reproducción de la especie. (HABERMAS, 1989, p. 506-507)

El entendimiento del mundo que propone la racionalidad comunicativa de Habermas resuena en las estrategias discursivas del desarrollo sostenible que buscan un consenso para la autoconservación del planeta más allá del dictado de un imperativo económico, ecológico o tecnológico y se abre a un diálogo de interpretaciones (simbólicamente estructurado) que no se sometería a las razones de fuerza mayor del sistema, participando en la estructuración de aquello que hay que conservar. Si bien las condiciones de la sustentabilidad no son las que emergen de una "conciencia de especie", la socialización comunicativa se da en fondo de saber establecido y del "mecanismo lingüístico" de reproducción de la especie.

Sin embargo, lo que justamente está en juego en la construcción de un futuro sustentable son las formas emergentes de significación del mundo y de la naturaleza, por lo que la política de la sustentabilidad no lleva a un consenso sobre la base de una racionalidad fundada en la inmanencia del lenguaje, sino de las estrategias de poder que promueven el saber de fondo de la ecología, del pensamiento sistémico y de la lógica del mercado, y de estrategias diferenciadas, divergentes y muchas veces antagónicas de reapropiación del mundo y de la naturaleza. La sustentabilidad posible será la resultante de estas tensiones -y sus vías políticas de resolución-, más que de una solución anticipada por la vía de un consenso a través de una racionalidad comunicativa que orienten la construcción de un "futuro común".

A partir de los presupuestos de la racionalidad comunicativa, Habermas analiza las relaciones actor-mundo como tipos puros de acción orientada al entendimiento y piensa que,

...analizando los modos de empleo del lenguaje puede aclararse qué significa que un hablante (...) entable una relación pragmática con: algo en el mundo objetivo (como totalidad de las entidades sobre las que son posibles enunciados verdaderos); con algo en el mundo social (como totalidad de las relaciones interpersonales legítimamente reguladas); con algo en el mundo subjetivo (como totalidad de las propias vivencias a las que cada quien tiene un acceso privilegiado y que el hablante puede manifestar verazmente ante un público), relación en la que los referentes del acto de habla aparecen al hablante como algo objetivo, como algo normativo o como algo subjetivo. (HABERMAS, 1990, p. 171) 
Habermas define así al saber como la experiencia subjetiva que puede trasladarse hacia el entendimiento y ser tematizada:

\begin{abstract}
...en cuanto el asunto se convierte en ingrediente de una situación, puede devenir sabido y ser problematizado como hecho, como contenido de una norma, como contenido de una vivencia. Antes de hacerse relevante para una situación, esa misma circunstancia sólo está dada en el modo de una autoevidencia del mundo de la vida con la que el afectado está familiarizado intuitivamente sin contar con la posibilidad de una problematización. Ni siquiera es algo "sabido" en sentido estricto, si el saber se caracteriza por poder ser fundamentado y puesto en cuestión. Sólo los limitados fragmentos del mundo de la vida que caen dentro del horizonte de una situación constituyen un contexto de acción orientada al entendimiento que puede ser tematizado y aparecer bajo la categoría de saber. (1989, p. 176)
\end{abstract}

La racionalidad comunicativa se constituye así desde el fondo de un saber, un saber que remite a la conciencia que se levanta por encima de la evidencia del mundo de la vida para poner a prueba su objetividad, para ser fundamentado y cuestionado, tematizado y problematizado. El saber sale de su interioridad para entrar en el ámbito de la norma, de la objetividad de la relación intersubjetiva, alejado de la relación ser-saber, de los saberes comunes diferenciados y de sus disensos. La otredad (el saber del otro, el saber en potencia, el no saber) queda fuera del entendimiento, para disolverse en la familiaridad de la cultura constituida por el saber común de formas de la inteligibilidad del entendimiento posible preestablecidas por las estructuras del mundo de la vida:

...las nuevas situaciones emergen a partir de un mundo de la vida que está construido a partir de un acervo cultural de saber que nos es siempre familiar. Frente a ese mundo los agentes comunicativos no pueden adoptar una posición extramundana, al igual que tampoco pueden hacerlo frente al lenguaje como medio de los procesos de entendimiento merced a los que el mundo de la vida se mantiene (...) Las estructuras del mundo de la vida fijan las formas de la intersubjetividad del entendimiento posible (...) hablante y oyente se entienden desde, y a partir de, el mundo de la vida que les es común, sobre algo en el mundo objetivo, en el mundo social y en el mundo subjetivo. (HABERMAS, 1989, p. 178-179)
La racionalidad comunicativa se mantiene dentro de una epistemología positivista y fenomenológica, desconociendo el campo de la comprensión existencial del ser en el mundo, del saber abierto al mundo no objetivo, del saber abierto a la diversidad de saberes y a la otredad, afirmando la necesidad de rescatar una razón universal capaz de iluminar las figuras opacas del pensa-miento mítico y las manifestaciones incomprensibles de las culturas ajenas:

La prueba definitiva de una teoría de la racionalidad con la que la comprensión moderna del mundo pudiera asegurarse de su universalidad, sólo estribaría en que las figuras opacas del pensamiento mítico se iluminaran y se aclararan las manifestaciones no-comprensibles de las culturas ajenas, y se aclararan de suerte que no sólo entendiéramos los procesos de aprendizaje que nos separan de ellas, sino que nos percatáramos también de lo que hemos desaprendido en el curso de nuestros procesos de aprendizaje. (HABERMAS, 1989, p. 568)

El saber ambiental y el diálogo de saberes emergen del cuestionamiento de ese "saber de fondo" por la crisis ambiental que vuelve problemáticos los mundos de vida modernos y tradicionales, y cuestiona la centralidad, la universalidad y la generalidad de un pretendido saber totalizante ordenador del proceso de globalización. La razón económica e instrumental y los procesos de racio-nalización en el entendimiento de la realidad han quedado saturados y rebasados. El tránsito hacia la sustentabi-lidad anuncia otro saber, otra racionalidad, que trascien-den lo pensable desde la ontología y la epistemología herederas de la metafísica.

La racionalidad comunicativa vendría a ser el intento póstumo para hacer inteligible el mundo -y los mundos de la vida - que ha generado la racionalidad cognitiva e instrumental. La acción social es movilizada -normada, legitimada- por lo comunicable racionalmente y cercada por los límites que esa razón impone a la invención de un futuro. El diálogo de saberes se establece dentro de una racionalidad ambiental que rompe el cerco de la racionalidad objetivante y se abre hacia la otredad; busca comprender al otro, negociar y alcanzar acuerdos con el otro, sin englobar las diferencias culturales en un saber de fondo universal ni traducir "lo otro" en términos de "lo mismo". El futuro se abre en un diálogo de saberes diferenciados, pero también con un "diálogo" abierto a lo 
inefable e invisible, en una atenta espera con las incógnitas de aquello que no se presenta al conocimiento objetivo y a la argumentación razonada; que no es inmanente a la ontología, a la razón y a la palabra. Las perspectivas de la sustentabilidad se despliegan así en el horizonte del encuentro del ser con la otredad.

\section{Ética, ontología y saber en Lévinas: el todo, el otro, el infinito}

La relación de otredad no es una de referencia con lo Real, de trascendencia del Ser o de transferencia con un gran Otro. La relación de otredad no es la que se establece en la polaridad que produce el pensamiento metafísico en la dualidad mente-cuerpo, sujeto-objeto, unidad-diversidad. La relación con lo otro se da en el orden del ser y del saber; pero sobre todo es deferencia, relación ética con el otro humano y no una relación ontológica, episte-mológica o fenomenológica. Si Heidegger encuentra la raíz del malestar de la cultura occidental en la disyunción entre el ser y el ente, Lévinas acusa un pecado original de raíces más profundas: el de la constitución del ser humano por el lenguaje. Desde allí recupera un sentido ético capaz de conmover los fundamentos ontológicos del pensamiento que cerca al ser y lo fija en la objetividad de un presente sin trascendencia ni escapatoria. Pues como afirma Lévinas, "el conocimiento objetivo, aunque siga siendo desinteresado, no por ello deja de estar marcado por el modo en el ser cognoscente ha abordado lo Real." (1997, p. 87-88)

Desde esa aseveración se devela otro sentido del discurso y del habla: aquél que se expresa al descubrirse el rostro y entrar en diálogo con un otro:

El rostro es una presencia viva, es expresión. La vida de la expresión consiste en deshacer la forma en la que el ente, que se expone como tema, se disimula por ella misma. El rostro habla. La manifestación del rostro es ya discurso (...) Esta manera de deshacer la forma adecuada al Mismo para presentarse como Otro, es significar o tener un sentido. Presentarse al significar, es hablar. (LÉVINAS, 1997, p. 89)

Lévinas, demarcándose de Heidegger, postula así una ética anterior y más allá de toda ontología:
La esfera primordial que corresponde a lo que llamamos el Mismo sólo se vuelve hacia lo absolutamente otro por la llamada del Otro. La revelación, con relación al conocimiento objetivante, constituye una verdadera inversión. En Heidegger ciertamente, la coexistencia es planteada como una relación con otro, irreductible al conocimiento objetivo, pero reposa también, a fin de cuentas, en la relación con el ser en general, en la comprensión, en la ontología. De antemano, Heidegger plantea este fondo del ser como horizonte en el que surge todo ente, como si el horizonte y la idea de límite que incluye y que es propia de la visión, fuesen la trama última de la relación. Además, en Heidegger, la intersubjetividad es coexistencia, un nosotros anterior al Yo y al Otro, una intersubjetividad neutra. El cara-acara, a la vez, anuncia una sociedad y permite mantener un Yo separado. (LÉVINAS, 1997, p. 91)

El Otro es rostro, pero también es lo otro del saber totalizador. El ambiente, en tanto que es un saber, aparece como esa externalidad (lo absolutamente Otro) del conocimiento objetivo que busca la mismidad entre la palabra y la cosa, la identidad entre el concepto y lo real, el reflejo del ente en el conocimiento. Por ello, el ambiente no es una dimensión internalizable o asimilable dentro de un sistema teórico, una economía del saber, o en los paradigmas objetivantes del conocimiento:

Si la totalidad no puede constituirse, es porque lo Infinito no se deja integrar. No es la insuficiencia del Yo la que impide la totalidad, sino lo Infinito del Otro (...) En la metafísica, un ser está en relación con lo que no podría absorber, con lo que no podría comprender, en el sentido etimológico de este término (...) El Mismo y el Otro no podrían entrar en un conocimiento que los abarcara. Las relaciones que sostiene el ser separado con el que lo trasciende no se producen sobre el fondo de la totalidad, ni se cristalizan en sistema. (LÉVINAS, 1997, p. 103)

La apertura y fertilidad del ser que surge del encuentro con lo otro es algo invisible, imprevisible desde una visión, un conocimiento y un saber que pudieran anticiparse a los "hechos", al advenimiento del ser en un devenir de lo posible ya inscrito en la potencia de lo real como epigénesis, novedad, azar y teleonomía. La llamada del infinito es la convocatoria a aquello que sólo podría provenir de un 
encuentro con un otro que no se conforma ni disuelve en la universalidad, generalidad, unidad o mismidad del pensamiento sobre el mundo presente. Lo que emerge en el encuentro con la otredad escapa a toda voluntad, a toda idea y a todo poder sobre su realización posible:

El Otro me mide con una mirada incomparable con aquella con la que lo descubro. La dimensión de altura en la que se coloca el Otro es como la curvatura primera del ser en la cual se sostiene el privilegio del Otro, el desnivelamiento de la trascendencia (...) El Otro no es trascendente porque sería libre como yo. Su libertad, al contrario, es una superioridad que viene de su trascendencia misma (...) La relación con el Otro no se convierte, como en el conocimiento, en gozo y posesión, en libertad. El Otro se impone como una exigencia que domina esta libertad, y a partir de aquí, como más original que todo lo que pasa en mí. El otro, cuya presencia excepcional se inscribe en la imposibilidad ética de matarlo (...) indica el fin de los poderes. Si no puedo más poder sobre él, es porque desborda absolutamente toda idea que puedo tener de él. (LÉVINAS, 1997, p. 109)

El saber (ambiental), con su criticidad de la razón dominadora, no es internalizable en los paradigmas científicos y no se disuelve su diversidad y diferencia en la totalidad del conocimiento objetivo ni en el saber de fondo que posibilita un consenso de saberes a través de una racionalidad comunicativa. Este "Otro" del conocimiento no se deja tematizar ni sistematizar; su "concepto" se retrae de todo afán de concreción y objetividad. El saber es

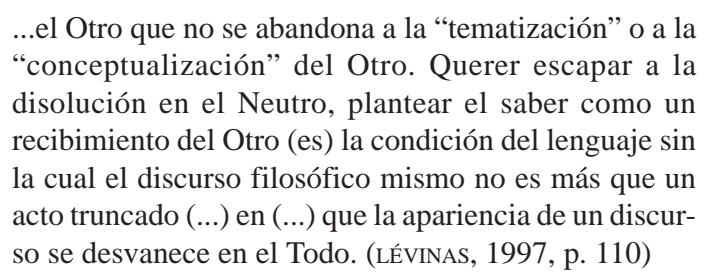

El Otro -los saberes-otros- no se subsume en un saber de fondo; los saberes en los que encarna no se unifican en un consenso guiado por principios de una racionalidad comunicativa. Esa es la condición del diálogo de saberes como un encuentro creativo que abre la puerta de salida a la autonomía subsumida en la homo-geneidad y universalidad del mundo, al a priori racional y al entendimiento de una existencia para sí, que glo-balizan y engullen a la diversidad en el forzamiento de una unidad. El diálogo de saberes conduce la hetero-nomía de un habla dirigida al otro, donde es posible dar el salto afuera de la realidad establecida para construir nuevos mundos de vida:

Hablar supone una posibilidad de romper y de comenzar. Plantear el saber como existir mismo de la creatura, como el remontarse, más allá de la condición hacia el Otro que funda, es separarse de toda una tradición filosófica que buscaba en sí el fundamento de sí misma, fuera de las opiniones heterónomas. Pensemos que la existencia para sí, no es el último sentido del saber, sino el retomar el cuestionamiento de sí, el retorno hacia el antes que sí en la presencia del Otro. La presencia del Otro heteronomía privilegiada- no dificulta la libertad, la invierte. La vergüenza de sí, la presencia y el deseo de lo Otro, no son la negación del saber: el saber es su articulación misma. La esencia de la razón no consiste en asegurar al hombre un fundamento y poderes, sino en cuestionarlo y en invitarlo a la justicia (...) El Otro no nos afecta como aquel que es necesario sobrepasar, englobar, dominar, sino en tanto que otro, independiente de nosotros: detrás de toda relación que pudiéramos mantener con él, que surge nuevamente absoluto. (LÉVINAS, 1997, p. 111)

El diálogo de saberes es un diálogo entre seres marcado por la heteronomía del ser y del saber, por una otredad que no se absorbe en la condición humana genérica, sino que se manifiesta en el encuentro de seres culturalmente diferenciados; de seres constituidos por saberes que no se reducen al conocimiento objetivo y a la verdad ontológica, sino que remiten a la justicia hacia el otro: justicia que no se disuelve ni se resuelve en un campo unitario de derechos humanos, sino en el derecho a tener derechos diversos de seres diferenciados por su cultura. El diálogo de saberes se forja desde la virtualidad de todo ser que se da en una trascendencia que es devenir, de lo sido-siendo abierto a lo por-venir que no habrá de emerger por la potencia de un desenvolvimiento ontológico (la autoorganización de la physis, la mutación genética, la epigénesis del desarrollo biológico y la emergencia de la noosfera). El saber se constituye y el diálogo de saberes se produce en la relación del ser con su externalidad infinita, en el encuentro con un 
ser-Otro, desde sus diferencias, en el horizonte de un infinito que anuncia un futuro no proyectable, no predecible, quizá inefable.

Lo que aún no es, no es la imposibilidad del ser, no es el desazón de la palabra que falta y de lo real inasible, sino la potencia de aquello que se encuentra, que nace y se construye desenmascarando la opresión del discurso y la realidad fijada por la palabra, develando el conocimiento que encubre el ser, desencadenando la potencia de lo real; sabiendo que el infinito no llega nunca a mostrar su rostro, que no es integrable en un ser pleno, que se produce movilizando las ausencias y la falta en ser, la fuerza del no, del aún no, del "menos que nada" (LÉvinAs).

La palabrería que articula los datos y los hechos (la realidad hecha por la denotación cosificadora) deja una estela de silencio, la imposibilidad de proferir una palabra lúcida y un acto salvador frente al cierre de la historia en la globalización mercantilizada y ecologizada. Lévinas desenmascara el efecto silenciador de este empirismo:

...el espectáculo del mundo silencioso de los hechos está embrujado: todo fenómeno enmascara, mistifica infinitamente, volviendo la actualidad imposible (...) Comprender una significación no es ir de un término de la relación al otro, percibir relaciones en el seno del dato. (LÉvINAS, 1997, p. 114)

Lévinas desplaza la verdad de la correspondencia entre lo real y el concepto, la palabra y la cosa, al juego infinito de pensamientos, razonamientos y saberes entre seres diversos, diferentes, diferenciados. Es desde este cuestionamiento de la representación de la realidad que la ética sale al rescate del ser de los desvaríos del conocimiento y el encerramiento de las ciencias. Desde allí se establece un encuentro con lo real y lo simbólico como potencia del ser no cosificado en la realidad avasallante de una "razón de fuerza mayor", lugar donde el diálogo de saberes abre, aún, un porvenir fundado en la otredad y la justicia. El saber trasciende al conocimiento fundado en la relación entre objetos. El diálogo de saberes parte de la interlocución con un otro que no está "dado". Contra todo empirismo, Lévinas afirma que

...el Otro es principio del fenómeno. El fenómeno no se deduce de él; no se lo encuentra al ascender a partir del signo que sería la cosa, hacia el interlocutor que emite ese signo sin un movimiento análogo a la marcha que conduciría de la apariencia a las cosas en sí. Porque la deducción es una manera de pensar que se aplica a objetos ya dados. El interlocutor no podría ser deducido, porque la relación entre él y yo es presupuesta por toda prueba. (LÉVINAS, 1997, p. 115)

El diálogo de saberes no es el diálogo intersubjetivo ni el de las cosas en sí puestas en comunicación como entes denotados, como una relación de objetos significados por la palabra. Lo que la palabra pone en juego es "aquello que se produce en el lenguaje", a saber, "el despliegue positivo de la relación pacífica con lo Otro sin frontera o sin negatividad alguna" (DERRIDA, 1998, p. 120). El diálogo de saberes sólo es posible dentro de una política de la diferencia, que no es apuesta por la con-frontación, sino por la paz justa desde un principio de pluralidad. Es en ese sentido que Lévinas afirma que "La unidad de la pluralidad es la paz y no la coherencia de elementos que constituyen la pluralidad." (LÉvinAS, 1997, p. 125).

El saber (ambiental) viene así a cuestionar al sistema discursivo que afirma la realidad realmente existente: la objetividad puesta en escena por una conciencia que emerge como representación de una realidad presente; la correspondencia de una racionalidad con el todo social que esta misma racionalidad ha generado. La otredad proviene del significante que se manifiesta al hablar, pensar y proponer "otro mundo" que está en otro lugar -utopía- del mundo objetivo presente. Como lo plantea Lévinas:

...la objetividad en la que el ser es propuesto a la conciencia no es un residuo de la finalidad (...) Se plantea en un discurso, en una negociación que propone el mundo. Esta proposición se realiza entre dos puntos que no constituyen un sistema, un cosmos, una totalidad (...) La objetividad del objeto y su significación provienen del lenguaje. Esta modalidad por la cual el objeto es puesto como tema que se ofrece, incluye el hecho de significar: no el hecho de remitir al pensador que lo acopla a eso que es significado (y que es parte del mismo sistema), sino el hecho de manifestar el significante, el emisor del signo, una alteridad absoluta que, sin embargo, le habla y, por lo mismo, tematiza, es decir, propone un mundo (...) El otro, el significante, se manifiesta en la palabra al hablar del mundo y no de sí, se manifiesta proponiendo el mundo, al tematizarlo. (LÉVINAS, 1997, p. 118-119) 
El saber ambiental (LEFF, 2001b) funda otra racionalidad, cuestionando el conocimiento que ha construido la realidad actual, controvirtiendo las finalidades preestablecidas y los juicios a priori de la racionalidad económica e instrumental. El discurso ambiental es palabra viva que propone un mundo nuevo desde signifi-cantes que asignan nuevos sentidos a lo real y a las co-sas; desde una palabra que no solo denomina y domina; desde un habla que espera un escucha y una respuesta. Es en este sentido que Lévinas afirma que "El lenguaje no exterioriza una representación preexistente en mi: pone en común un mundo hasta ahora mío." (LÉVINAS, 1997, p. 192). La significación y la inteligibilidad del mundo no provienen pues de la falta del Mismo y su necesidad de completarse, sino del "deseo del Otro":

...la significación se sostiene en el Otro que dice o que entiende el mundo y al que su lenguaje o su entendimiento precisamente tematizan. La significación parte del verbo en que el mundo es, a la vez, tematizado o interpretado, en el que el significante no se separa nunca del signo que emite, sino que recobra siempre al mismo tiempo que expone (...) La significación de los seres no se manifiesta en la perspectiva de la finalidad, sino en la del lenguaje. Una relación entre términos que se resisten a la totalización (...) La resistencia de un término al otro no señala aquí el residuo oscuro y hostil de la alteridad, sino, por el contrario la inagotable excedencia de delicadeza de la palabra (...) La palabra es siempre un recuperar lo que siempre fue simple signo arrojado por ella, promesa siempre renovada de esclarecer lo que fue oscuro en la palabra. (LÉvINAS, 1997, p. 119-120)

El diálogo de saberes no se conduce por la fórmula de racionalidad comunicativa basada en significados objetivos y en códigos de racionalidad preestablecidos por un saber de fondo común; el diálogo de saberes es el encuentro de interlocutores que rebasa toda concep-tualización, toda teoría y toda finalidad guiada por una racionalidad, que antepone la justificación de una racionalización a la razón y la justicia del Otro. Pues como acierta Lévinas,

...la "comunicación" de las ideas, la reciprocidad del diálogo, ocultan ya la esencia profunda del lenguaje. Esta reside en la irreversibilidad de la relación entre Yo y el Otro (...) el lenguaje sólo puede hablarse, en efecto, si el interlocutor es el comienzo de su discurso, si permanece en consecuencia, más allá del sistema, si no está en el mismo plano que yo (...) Los interlocutores como singularidades, irreductibles a los conceptos que constituyen al comunicar su mundo y al apelar a la justificación del Otro, presiden a la comunicación. La razón supone estas singularidades o estas particularidades, no a título de individuos ofrecidos a la conceptualización o que se despojan de su singularidad para recobrarse idénticas, sino precisamente como interlocutores, seres irremplazables, únicos en género, rostros. La diferencia entre las dos tesis: "la razón crea las relaciones entre el Yo y el Otro" y "la enseñanza del Yo por el Otro crea la razón" no es puramente teórica." (LÉVINAS, 1997, p. 124-263)

El encuentro cara-a-cara no es un encuentro en el imaginario de lo visible o en los reflejos de la representación. Lo simbólico que se expresa en el rostro vuelve a las fuentes del enigma del lenguaje, la confluencia de significaciones y la disputa de sentidos que emanan de la organización simbólica de lo real y se expresa en la diversidad cultural. El encuentro con la otredad que entre en juego por el lenguaje y el habla, más allá del nombrar lo nuevo, abre el camino a la realización de "lo que aún no es". Pero la emergencia de lo inédito y lo innombrable pasa también por esa llamada al ser desde el lenguaje, del "todavía no del lenguaje" que evoca y convoca la poesía:

...el poeta; a pesar de todo, el poema (...) Para ser lo que debe, lo que es capaz de ser -un acto de acerca-miento, un movimiento hacia el Otro- debe comenzar con el reconocimiento de su disparidad, admitir de una vez por todas que habla desde otro ámbito y que no puede imponerse, que debe contentarse con ofrecerse a sí mismo, aunque nadie lo solicite, en su desnudez, en el silencio que lo rodea. Ningún poema puede nacer de la convicción que ya existe un lenguaje que une dos cosas distintas; aún debemos crear y descubrir el todavía-no del lenguaje: el anhelo de una utopía, de un sitio inexistente. Como si desde este punto del vacío por fin pudiéramos continuar y averiguar donde estamos (AUSTER, 1996, p. 18-19, del prólogo de Jordi Doce).

El diálogo de saberes no aspira a la analogía ni a la reducción de la diversidad de sentidos en las homologías 
de significantes, en su sumisión a un discurso que recoja sus puntos comunes haciendo de lado sus diferencias, sus polisemias, sus silencios y sus significaciones creativas. El diálogo de saberes produce lo absolutamente nuevo en la fusión de los elementos que se encuentran, como en una reacción química, donde las propiedades de la molécula y del nuevo compuesto no están contenidas en sus átomos y sus elementos originarios; o a la producción de sentido y de lo real que surge de las sinergias de la pluralidad y la diversidad cuando

...la rima que crean (...) altera la realidad de cada uno. De la misma manera que dos objetos físicos, cuando se les aproxima uno del otro, generan fuerzas electromagnéticas que no sólo afectan la estructura molecular de cada uno, sino también el espacio entre ellos, alterando su propio ambiente, así dos (o más) eventos que riman establecen una conexión en el mundo, agregando una sinapsis más a ser transitada a través del vaso pleno de la experiencia (AUSTER, 1988, p. 161).

Pero el diálogo de saberes no es una química, ni una genética ni una poética, pues allí los elementos no se funden, no riman; se encuentran desde su otredad absoluta; la armonía de sus contrapuntos no eliminan las disonancias y desentendidos entre paradigmas y formaciones discursivas, entre el habla y la escucha. Mas ¿qué es aquello que se produce en el chispazo de ese encuentro de otredades y diferencias en esa virtualidad de la producción de sentidos asignados a la naturaleza por la creatividad de la palabra y la fertilidad del diálogo de saberes? Pues no basta afirmar que "el mundo llega a ser objeto. Ser objeto, ser tema, es ser aquel del cual puedo hablar con alguien que ha atravesado el plano del fenómeno y me ha asociado a él" (LÉVINAS, 1997, p. 122). La racionalidad ambiental complejiza el encuentro con la otredad que se da en la epifanía del rostro. Estamos asociados por formas diferenciadas de significar lo real, el fenómeno, la realidad objetiva (la naturaleza) que quedan fijados por la palabra. La palabra encadena significantes y fija significados, al tiempo que desenca-dena nuevos sentidos. Al mismo tiempo, el encuentro entre matrices de racionalidad que articulan lo material y lo simbólico en una diversidad de identidades culturales, está dominado por estrategias de poder en el saber, por encubrimientos ideológicos que velan las miradas, que sujetan a los sujetos, y que el encuentro cara-acara no alcanza a develar.
El diálogo de saberes está habitado por el no saber, por lo indecible, por una huella que está antes y más allá de la palabra, más allá del ser y del saber. Es la apertura a la idea de infinito alimentado por el hambre del deseo. La huella, dice Lévinas, es "el más allá del que proviene el rostro". Es

...el Ausente absolutamente perimido, absolutamente pasado, retirado en aquello que Paul Valéry llama profond jadis, jadis jamais assez y que ninguna introspección sabría descubrir en Sí (...) La idea del infinito es Deseo. Consiste, paradójicamente, en pensar más de lo que es pensado, conservándolo sin embargo en su desmesura en relación con el pensamiento, en entrar en relación con lo inasible, garantizando su estatuto de inasible. (LÉVINAS, 2000, p. 67-64)

El saber que habita al ser lleva a cuestas la huella de algo que fue, que no procede de, sino que precede a mi existencia, que no logro pensar, comprender, decir. Holocausto del pensamiento por obra del orden simbólico. Renacimiento desde la palabra, el habla y el encuentro con la otredad.

El infinito al que remite la relación de Otredad y al cual nos invita Lévinas, el tiempo que fragua en el campo del saber, el futuro que abre el diálogo de saberes, no podría ser un tiempo cronológico; ni siquiera se reduce al tiempo existencial al que nos remite la ontología heideggeriana, el del ser para la muerte, de una tempo-ralidad inscrita en el ser ahí. En el prefacio al libro que recoge el curso que en 1946-1947 donde esboza las ideas (una fenomenología de la alteridad y de su trascendencia) que habrán de dejar la huella a ser recorrida en su pensamiento posterior y póstumo, Lévinas reflexiona y evalúa 30 años después, en la madurez de su pensa-miento (Le Temps et l'Autre fue publicado en 1979), la idea de tiempo que allí se anunciaba:

El Tiempo del Otro no presenta el tiempo como horizonte ontológico del ser del ente, sino como modo del más allá del ser, como relación del pensamiento con lo Otro mediante diversas figuras de la socialidad frente al rostro de otro hombre: erotismo, paternidad, responsabilidad, respecto del prójimo- como relación con lo Absolutamente Otro, con lo Trascendente, con lo Infinito. Una relación o una religión que no está estructurada como saber, es decir, como intencionalidad (...) El tiempo (...) significaría, en su diacronía, una relación que no com- 
promete la alteridad del otro, asegurando sin embargo su no-indiferencia al "pensamiento". (LÉvinAs, 1993, p. 68)

El tiempo del otro se inscribe en el diálogo de saberes como una apertura hacia lo impensable (para una tradición, un paradigma, una racionalidad) del pensa-miento del otro y de aquello que queda fuera del campo de significación y comprensión de un conocimiento, de una teoría, de una cosmovisión. El diálogo de saberes se sitúa en la perspectiva de esta relación de otredad, en su horizonte de trascendencia del ser, en una espera activa con lo impensado y el no saber. El diálogo de saberes no se produce con la intención y la finalidad de reabsorber cosmovisiones y racionalidades diferenciadas en un código común de lenguaje de un mundo acabado, presente, globalizado, sino que se proyecta en la creación de un mundo futuro, de otro mundo posible; de un mundo hecho de muchos mundos, de diversidad cultural e identidades diferenciadas.

Esta postura incorpora al saber la condición del ser más allá de todo conocimiento: la agencia de lo no pensado; la productividad de lo invisible. La producción de la historia a partir de esa relación de otredad no es una relación de conocimiento. Como afirma Lévinas, se trata de una:

...relación con aquello que, siendo de suyo inasimilable, absolutamente otro, no se dejaría asimilar por la experiencia, o con aquello que, siendo de suyo infinito, no se deja comprender (...) Una relación con un Invisible cuya invisibilidad no procede de la incapacidad del conocimiento humano sino de la ineptitud del conocimiento en cuanto tal -de su inadecuación- frente al Infinito de lo absolutamente otro. (LÉVINAS, 1993, p. 69-70)

Se trata pues de conectar el saber con ese secreto nunca develado por una ontología o por una epistemo-logía al que se refiere Derrida, como esa sombra invisible e inefable del ser, más allá de la conciencia y de la intencionalidad representativa que lleva a preguntar quien es ese yo que habla:

...el secreto que es para el otro es lo que se revela sólo para el otro (...) Al denegar este secreto, la filosofía habría llegado a residir en un malentendido de lo que hay que conocer, a saber, que hay secrecía y que es inconmensurable con conocer, con el conocimiento y con la objetividad, como en la "interioridad subjetiva" inconmensurable que extrae Kierkegaard de cada relación del conocimiento del tipo sujeto/objeto (...) Quizá sea allí donde encontramos el secreto de la secrecía, a saber, que no es una cuestión de conocer y que está allí para nadie. Un secreto no pertenece, nunca puede decirse que esté (chez soi) (...) Tal es el Unheimlichkeit del Geheimnis, y debemos cuestionar sistemáticamente el alcance de este concepto y sus funciones, de forma regulada, en dos sistemas de pensamiento que se extienden igualmente, aunque en diferentes maneras, más allá de la axiomática del sí mismo o del chez soi como ego cogito, como conciencia de la intencionalidad representativa, por ejemplo, y de manera ejemplar en Freud y Heidegger. La cuestión del yo mismo (self): "quién soy yo?", no en el sentido de "quién soy yo", sino "quien es ese yo" que puede decir "quién"? Qué es el "yo", y que pasa con la responsabilidad una vez que la identidad del "yo" tiembla en secreto? (DERRIDA, 1996, p. 92)

La idea de eso otro no cognoscible cuestiona la idea del saber y del conocimiento que ha generado el pensamiento metafísico y filosófico. Mas si el horizonte del devenir al que abre la otredad se da en una relación que está más allá del ser y no está estructurada como un saber, no por ello es indiferente al pensamiento. Si bien la relación del pensamiento con lo Otro entraña una relación más allá de toda ontología y de toda episte-mología, no por ello es ajena al ser y al saber, a la relación del ser con el saber. El vínculo del ser con el saber no es una relación de conocimiento, de representación de la realidad en el pensamiento, de identidad entre concepto con lo real. Pero la relación ética del encuentro "cara-a-cara" con el Otro tampoco se produce en un mundo separado del orden ontológico: de la potencia de lo real que se despliega en el tiempo hacia un futuro de posibilidades; de un ser ahí que, en el orden del sujeto y más allá del carácter genérico del ser humano (del ser para la muerte), encarna como ser en el mundo, arraiga en formas de identidad que sin estar enclavadas en un orden intemporal y mantenerse inmutables dentro de una estructura mítica, que más allá de toda esencialidad como marca inalterable de un origen que garantizara su inmanencia en el tiempo, conserva y proyecta lo sido hacia lo que aún no es. Pero al mismo tiempo, en esa relación de otredad, el tiempo se abre hacia algo nuevo que no está prefigurado ni determinado por la generatividad de la physis y la potencia de lo real; que está más allá del ser, de toda ontología y toda epistemología. 
Es en este sentido que podemos retomar las palabras de Lévinas cuando apunta que:

...como modalidad del ser finito, el tiempo debería significar (...) la dispersión del ser del ente en momentos excluyentes y que, además, en cuanto instantes inestables o infieles a sí mismos, son expulsados uno a uno hacia el pasado, fuera de su propia presencia, suministrando no obstante la idea fulgurante de esta presencia y sugiriendo su sentido y su sin-sentido, la muerte y la vida. (LÉVINAS, 1993, p. 68-69)

El saber se produce en el horizonte de una diacronía que trasciende a la sincronía de los tiempos que con-fluyen en un presente, a los procesos ambientales que definen una estructura sincrónica interdisciplinaria, incluso de la conciencia que emerge orgánicamente de la evolución del cosmos hacia la génesis de una noosfera. En ese sentido, el diálogo de saberes se inscribe en la perspectiva de una "diacronía (que) sea más que una sincronización, (donde) la proximidad sea más preciosa que el hecho de darse, que la fidelidad de lo inigualable sea mejor que la conciencia de sí." (LÉVINAS, 1993, p. 70)

En este sentido, la relación con lo Otro y la idea de Infinito desde el tiempo del Otro, permiten pensar el saber ambiental como el campo de externalidad (el Otro) del conocimiento científico, y el diálogo de saberes como la relación de otredad que abre la historia hacia un futuro sustentable. Allí se construye el campo de la racionalidad ambiental en el que las ciencias y la economía se con-frontan con ese Otro absoluto que es el Ambiente. En ese encuentro se van constituyendo identidades estratégicas que van dialogando con otras que le son semejantes en cuanto a su diferenciación con el Mismo común (el pensamiento único); singularidades que ha-brán de situarse siempre como uno frente a otro, haciendo ética, política y pedagógica su relación de otredad. Esta es la fecundidad del diálogo de saberes que, partiendo de la condición existencial del ser y de la ética de la otredad, se despliega en un campo de diversidades culturales (LEFF, 2003a).

\section{Más allá de la totalidad y del sistema: de la interdisciplinariedad al diálogo de saberes}

La crisis ambiental ha sido asociada al fraccionamiento del conocimiento; de esta manera, la comprensión del mundo actual ha reclamado un pensamiento de la complejidad; la interdisciplinariedad y la teoría de sistemas emergen como dispositivos metodológicos para la constitución de un saber holístico. Estos nuevos enfo-ques buscan reintegrar las partes fragmentadas de un todo de conocimiento que, si bien pone el acento en las interrelaciones de los procesos, no renuncia a los prin-cipios de objetividad de la ciencia. Tanto la interdisci-plinariedad como la teoría de sistemas se mantienen dentro del cerco del logocentrismo de las ciencias, de la matematización del saber, de la certidumbre y control del mundo; conservan el espíritu de la unidad de la ciencia y la universalidad del conocimiento, así como el principio de verificación y falsificación de las teorías con la realidad. La interdisciplinariedad y las teorías de sistemas son las nuevas herramientas de un saber totalitario que se resiste a comprender el lugar de exterioridad que ocupa el saber ambiental dentro de la esfera del conocimiento científico.

Entre las mallas de las teorías de sistemas y los métodos interdisciplinarios se escurre la onda ontológica de lo real y las significaciones asignadas a la realidad que escapan a los paradigmas formales del conocimiento, así como los saberes que no se hayan en la misma frecuencia de las ciencias y por tanto no se integran en una mismo sistema de conocimiento. Las teorías y disciplinas científicas constituyen paradigmas que edifican obstáculos epistemológicos que se erigen en barreras para la reintegración de los saberes que orbitan en sus espacios de externalidad. El saber ambiental problematiza a las teorías constituidas para internalizar en ellas una "dimensión ambiental" que constituye el lado oscuro de lo impensable de sus paradigmas de conocimiento. Sin embargo, el saber ambiental no viene a completar la falta de conocimiento de las ciencias ni su propósito es retotalizar y reunificar al conocimiento (LEFF, 2001a). El ambiente es la falta incolmable de conocimiento de las ciencias. Es la exterioridad del saber ambiental lo que cuestiona el encerramiento del conocimiento objetivante, que al forzar la unificación del saber, genera el fraccio-namiento de las ciencias y el desconocimiento del saber. El saber ambiental es el actor disidente del proyecto epistemológico totalitario de las ciencias. 
La sustentabilidad aparece en el horizonte de esta desconstrucción de la historia, mas no podrá plantearse como un objetivo a ser alcanzado por la vía de la racionalidad cognitiva e instrumental. La sustentabilidad no es decidible desde el conocimiento (de la interdisciplinariedad, de la prospectiva tecnológica, de la gestión científica). El futuro sustentable, como construcción social, es un campo abierto a lo posible, generado en el encuentro de otredades en un diálogo de saberes.

La construcción de un futuro sustentable sin duda requiere un diálogo abierto capaz de acoger visiones y negociar intereses contrapuestos en la apropiación de la naturaleza; mas no habrá de producir consensos basados en visiones homogéneas ni limitarse a negociar conflictos emergentes. El diálogo de saberes se plantea desde el reconocimiento de los saberes -autóctonos, tradiciona-les, locales-que aportan sus experiencias y se suman al conocimiento científico y experto; pero implica a su vez el disenso y la ruptura de una vía homogénea hacia la sustentabilidad; es la apertura hacia la diversidad que rompe la hegemonía de una lógica unitaria y va más allá de una estrategia de inclusión y participación de visiones alternativas y racionalidades diversas cuyas diferencias serían zanjadas por una racionalidad comunicativa.

En este sentido, la apuesta por una política de la diferencia está llevando a la reinvención de identidades culturales y al diseño de nuevas estrategias de reapro-piación de la naturaleza. Esta política se establece en un espacio de confrontación, resistencia y negociación con la globalización económico-ecológica que se encuentra y se enfrenta con su Otro en las comunidades indígenas y campesinas locales. En el diálogo de saberes se pone en juego un proceso de reapropiación de saberes, de conocimientos, de discursos. Es un campo de debate, con-frontación y disputa de sentidos en el que se constituyen nuevas identidades, desde las cuales se abre un diálogo de saberes entre comunidades y un intercambio de expe-riencias entre sociedades campesinas e indígenas. Es la apuesta política de esa hospitalidad lévinasiana, donde la identidad cultural recibe al otro (a las otras) comunidades fuera de la totalidad sistémica, como un acto de solidaridad en el que se potencian mutuamente y donde surge algo nuevo e inédito en el campo de la historia.

El diálogo de saberes se plantea en la fecundidad de la otredad que abre un porvenir que no está dado ni en la extrapolación del presente ni en la conducción racional de un proceso de desarrollo fundado en el conocimiento. El futuro -el porvenir- está más allá de la generatividad del mundo material, de la novedad que emerge de la evolución biológica y la mutación genética, de la invención e innovación tecnológica. Está más allá del devenir y de la trascendencia como expresión de algo contenido de antemano dentro de un orden ontológico, epistemológico y fenomenológico; como una potencialidad del ser, de lo real y del lenguaje. La otredad, como el encuentro entre yo y tú, de lo Mismo con lo Otro, abre un mundo hacia lo que puede llegar a ser en el encuentro y diálogo entre seres hablantes.

Si el ser se trasciende en su relación con lo otro, ello significa que el futuro no es sólo actualización y trascendencia de la potencia de lo real, del elemento que despliega su ser liberado de las barreras y cadenas que le impone la realidad, el interés, la economía, la razón. El porvenir no es el desarrollo dialéctico del ser o de la materia hacia un futuro sustentable como potencia de lo real, de la razón o de la conciencia. Sin duda se sostiene y funda en la potencia de lo real y se despliega en un proceso de apropiación de esa potencia por el pensamiento; pero es impulsado por el deseo y por la apertura hacia la otredad, que trasciende (está más allá de) la realidad, del ser y de la existencia.

Lévinas trasciende la fijación objetivista y el cerco totalitario de la epistemología y la ontología, para llevarnos a comprender la construcción del mundo - su objetivación- a partir de la otredad; no escapa sin embargo a una ética basada en una concepción humanista de la existencia guiada por el gozo, la satisfacción, la felicidad, de la ética como forma suprema de la condición humana que rige la significación del ser y nuestro actuar en el mundo. Esta visión lévinasiana se enlaza a la com-prensión del ambiente como lo Otro de la ciencia y al diálogo de saberes, que no sólo reconoce lo inédito, lo incomprensible y lo inefable del Otro que aparece en la injusticia y la desigualdad, sino también el derecho a la diferencia y de lo absolutamente otro de las identidades no asimilables a un código superior de conocimiento y justicia. La racionalidad ambiental incorpora en las relaciones de otredad al "otro cultural", a la variedad de formas de comprensión y significación del mundo que abren la vía de construcción de un futuro sustentable a partir de las formas de ser y de saber de los pueblos. El diálogo de saberes se inscribe en una racionalidad ambiental que lleva a la desconstrucción de la globalización totalitaria del mercado para abrir paso a la construcción de sociedades sustentables a partir de sus formas diversi-ficadas de significación de la naturaleza. 
La sustentabilidad no es la ecologización del planeta y está más allá de los consensos que unifican mundos de vida orientados por una racionalidad comunicativa hacia un futuro común. El destino es un infinito que se forja en el encuentro de muchos mundos, de mundos que se miran con otros ojos, que lo moldean de otras formas. Los saberes que allí se encuentran admiten la inclusión del no ser en el ser en una relación que no es una dialéctica. El diálogo de saberes se establece en un campo de fuerzas donde la creatividad del lenguaje y el habla trascienden a la rima de los significados asignados a la realidad y a la innovación pura de la palabra. Es un diálogo habitado y habilitado por el poder. La producción de sentidos en el campo de la sustentabilidad emerge dentro de estrategias de poder en el saber. La disputa de sentidos en torno a la sustentabilidad no resulta de una polisemia de significantes, sino de estrategias de valorización y apropiación de la naturaleza.

Las nociones de desarrollo sustentable o sostenible adquieren su sentido dentro de formaciones discursivas organizadas por estrategias de poder, sea por la recodificación de la naturaleza (de los bienes y servicios ambientales) en términos económicos y valores de mercado, sea por la valorización cultural de la naturaleza. Las nociones de desarrollo, de biodiversidad, de territorio, de autonomía, emergen para configurar estrategias que movilizan acciones sociales, que legitiman derechos, que reinventan identidades asociadas con la reapropiación social de la naturaleza. Estas estrategias de poder en el campo del saber ambiental se despliegan en el diálogo de saberes entre intelectuales y grupos de base en la invención de discursos teóricos y políticos que se entretejen, se hibridan, se mimetizan y se confrontan en un diálogo entre las comunidades y la academia, entre la teoría y la praxis, entre el saber indígena y el conocimiento científico de la naturaleza.

La epifanía del rostro como ética que trasciende a la ontología del ser, debe repensarse así como un encuentro entre seres y un diálogo de saberes en la perspectiva de una racionalidad ambiental, replanteando la relación sociedadnaturaleza, materia-cultura, real-simbólico. Pues junto con la ética de la otredad del tú y yo, de la ruptura con la mismidad que funda la metafísica y la ciencia aparece ese Otro -el ambiente- como externalidad del logos (de las ciencias objetivantes, de la realidad generada como reflexión del conocimiento sobre lo real). El saber ambiental emerge allí como lo absolutamente Otro de las ciencias cerradas en sus objetos de conocimiento. El Ambiente produce una significancia que trasciende toda posible transmutación del Otro en lo Mismo, la absorción de los diferentes niveles de generatividad de la materia (del cosmos a la biosfera y a la noosfera) en un orden ecológico y un pensamiento holístico que reabsorbe sus diferencias en una nueva totalidad sistémica. El saber ambiental y el diálogo de saberes conducirían así a una "experiencia de lo totalmente exterior, tan contradictorio en los términos como una experiencia heterónoma?" (LÉVINAS, 2000, p. 53)

La máxima ética que se expresa en la epifanía del rostro en el mandamiento del "no matarás", trasciende en el orden de una racionalidad ambiental al respeto de la vida del prójimo para dejar ser a la vida y dar vida al ser. Ello implica el no matar la diversidad de formas de vida y formaciones culturales; dejar ser a la naturaleza y los significados culturales, la riqueza de seres y saberes.

El diálogo de saberes desactiva la violencia que se ejerce por la homogenización forzada del mundo diverso, por la sumisión de voluntades y visiones diferenciadas a un discurso universal sobre "nuestro futuro común", por la sujeción a un sistema (lógico, ecológico, económico) que desustantiva al ser para someterlo al poder de una lógica suprema (economización de la naturaleza, del hombre, de la cultura).

El diálogo de saberes se inscribe en la desconstrucción del mundo globalizado atrapado en las formas de representación de la realidad que produce el logocentrismo y el pensamiento único. Pues como apunta Lévinas:

...la relación con las cosas, la dominación de las cosas, esta manera de estar sobre ellas, consiste precisamente en no abordarlas jamás desde su individualidad (que) sólo existe (y es) accesible a partir de la generalidad, a partir de lo universal, a partir de las ideas, a partir de la ley. Nos hacemos de la cosa a partir de su concepto. La violencia, que parece ser la aplicación de una fuerza a un ser, en realidad, niega al ser toda su individualidad, tomán-dolo como elemento de su cálculo y como caso particular de un concepto. Esta manera de la realidad sensible de ofrecerse a través de su generalidad, de tener un sentido no a partir de ella misma, sino a partir de relaciones que sostiene con todos los otros elementos de la repre-sentación (de un sistema) y en el seno de una repre-sentación que ya se ha apoderado del mundo, es lo que puede llamarse la forma de esta realidad. (LÉVINAS, 2000, Liberté et commandement, p. 86-87). 
En esta denuncia de la violencia del concepto, de la teoría y el pensamiento sistémico, Lévinas parece reivindicar los saberes subyugados bajo el peso del poder de un orden lógico supremo, de una ley universal, de los saberes institucionalizados, cuya mejor autopsia nos ha sido legada por Michel Foucault. Contra la violencia del sujetamiento a las relaciones sistémicas bajo el dominio de la racionalidad económica y la racionalidad instrumental, se levanta la voz de la otredad a través del diálogo de saberes. Es allí donde Lévinas hace intervenir la expresión del rostro, que más que el reflejo de un pensamiento que anima al conocimiento del otro, convoca a un acto de interlocución en el que seres diferentes se subordinan uno al otro dentro de un diálogo de saberes donde se establece un campo de sentidos plurales que provienen de la diversidad del ser. En este diálogo adquieren expresión seres culturales constituidos por sus saberes, cuyos conflictos podrán resolverse en el consenso generado a través de una racionalidad comunicativa, pero que no disuelven sus diferencias en el conocimiento del otro o en un saber de fondo común:

...lo que es expresado no es un pensamiento que anima al otro, es también el otro presente en ese pensamiento. La expresión torna presentes lo comunicado y el comunicante, ellos se confunden en ella. Pero eso no quiere decir tampoco que la expresión nos brinda conocimiento del otro. La expresión nos habla de alguien, no es un dato sobre una coexistencia, no suscita, además del saber, una actitud; la expresión invita a hablar a alguien. La actitud más directa hacia un ser (...) no es el conocimiento que podemos tener de él, sino precisamente el comercio social con él (...) El ser presente domina o penetra su propia aparición: él es interlocutor. Los seres que se presentan uno a otro, se subordinan uno al otro. Esta subordinación constituye el acontecimiento primero de una transición entre libertades y de un mandamiento (...) Un ser manda a otro, sin que eso sea simplemente en función de un todo que abraza, de un sistema, y sin que esto sea por tiranía. (LÉVINAS, 2000, p. 88)

Al decir de Lenger (en su entrevista a Lévinas), éste "muestra fenomenológicamente que el Decir del otro antecede al Cogito y que inaugura por vez primera cada sentido posible de cada pensamiento posible." (LÉVINAS, 2000, p. 105). La fenomenología de Lévinas desplaza la subjetividad trascendental hacia la exterioridad del ser, que es al mismo tiempo la exteriorización del conocimiento hacia el saber en relación con el ser y lo real y no sólo del yo en relación con el prójimo. El diálogo de saberes reenlaza así la ética, la ontología y la epistemología. Es el trenzado de lo real, lo simbólico y lo imaginario tensado por la otredad situada en la diversidad cultural.

El diálogo de saberes cuestiona el proyecto totalizante del conocimiento objetivo y la fijación del conocimiento en el presente, de la historia basada en "hechos", de un futuro limitado a la extrapolación de las tendencias de la realidad, sin cambio, sin creatividad, sin posibilidad. El diálogo de saberes parte de la idea de pensar la relación entre el ser y el saber, de la reapropiación del mundo desde la reconstitución de la identidad; abre el concepto genérico del ser (HEIDEGGER) para pensar la diversidad del ser cultural dentro de una política de la diferencia.

El diálogo de saberes pone en relación seres y saberes que no se subsumen ni retotalizan como simples variantes de lo Uno y lo Mismo. Son relaciones de otre-dad en cuanto a sus diferencias irreconciliables; pero que al mismo tiempo se dan en un fondo de Otredad, en un espacio y un tiempo que están fuera de la positividad del conocimiento, en la esfera de un saber ambiental como Otro del conocimiento, en esa trascendencia que no es la del "desarrollo" de aquello que está en la inmanencia del ser y en la potencia de lo real, sino en ese devenir hacia un futuro más allá del presente, en ese Infinito que está más allá de la trascendencia orgánica, fenome-nológica o dialéctica. Es la condición existencial del existente-del ser simbólico-, lo que abre el mundo a un haz de diferenciaciones que, siendo ramas de una misma condición humana, configuran identidades que se viven, se encuentran y dialogan desde la relación de constitución del ser-saber que reconoce su alteridad fundamental, su diferencia radical, su irreconciliable otredad.

Es en este sentido que Lévinas afirma que, "el porvenir es la relación misma con lo otro”. (LÉvinAs, 1993, p. 117). El encuentro de saberes se produce más allá de la conciencia y del conocimiento, ya que,

La intencionalidad de la conciencia permite distinguir al yo de las cosas, pero no hace desaparecer el solipsismo [que como afirma Lévinas no es un sofisma, sino la estructura misma de la razón] porque su elemento, la luz, nos hace dueños del mundo exterior, pero es incapaz de encontrarnos un interlocutor. La objetividad del saber racional no elimina en absoluto el carácter solitario de la razón." (LÉVINAS, 1993, p. 105) 
El diálogo de saberes no es pues lo que se pone en juego en la intersubjetividad de la racionalidad comunicativa; no disuelve las diferencias en un consenso. Si bien es cierto que las contradicciones entre interlocutores y actores sociales remiten al campo político de la "reso-lución de conflictos", donde se negocian intereses y se alcanzan acuerdos, esto no disuelve las diferencias entre seres culturales. Por ello el diálogo de saberes, más que una fusión o reconciliación entre opuestos, produce una demasía que se da en el encuentro con los demás. Lo que abre la historia hacia el porvenir de un futuro sustentable en el diálogo de saberes, no es sólo lo incognoscible, lo irrepresentable de eventos que aún no afloran a la realidad y al pensamiento, sino también esa relación del saber con lo real y la existencia que, sin dejar de tener referentes en la realidad, está en un espacio de externalidad del conocimiento y de la objetividad del presente.

El futuro sustentable no es el devenir de una conciencia colectiva, la comunión de una colectividad de un consenso común de toda la humanidad frente a la crisis ambiental. La construcción social de la sustentabilidad se da en otra dimensión de lo posible y de la creatividad que pudieran provenir desde la conciencia del sujeto. Pone en juego aquello que emerge de relaciones de otredad. No es tan sólo la relación que surge del encuentro de individuos que se comunican desde su yo mismo; también enfrenta y concilia identidades colectivas que se presentan ante un yo privado. Esos "comunes" no se disuelven en lo que tiene de común la humanidad, en la generalidad de lo humano, en una conciencia de especie. Junto con la individualidad del yo, el hecho humano se organiza en formaciones culturales diferenciadas, en colectividades de seres con identidades propias que se reconfiguran y actualizan en una relación con el saber, de estrategias de poder en el saber, que se definen en relación con la naturaleza, con los otros culturales y con ese Otro que es la racionalidad modernizadora.

La otredad que conforma el campo de fuerzas donde se produce el diálogo de saberes, está más allá de la positividad del conocimiento que fija la realidad en un presente; de un principio hologramático y un pensamiento holístico, donde la parte está en un todo y el todo en cada parte en una totalidad de interrelaciones sin otredades. Las relaciones de otredad no son una dialéctica donde el contrario fuera internalizable como un alter ego dentro de un sistema; no es una alteridad asimilable en un movimiento predecible o en una argumentación predicable, en el contenido en una estructura, en un desdoblamiento del ser, o en la producción de una novedad, en la emergencia de una conciencia de sí a partir de un fundamento ecológico del ser.

El saber ambiental no se justifica por la certeza de sus postulados y su correspondencia con la realidad. Su sentido más fuerte es el que establece con la utopía, como pensamiento que moviliza la construcción de otros mundos posibles y nuevas realidades sociales, abriendo el cerco del conocimiento consabido. El saber ambiental no sólo se manifiesta en el modo propositivo y argumen-tativo del discurso en el campo conflictivo de los sentidos de la sustentabilidad. También se encarna en los imaginarios colectivos, las cosmovisiones y formaciones simbólicas que se plasman en los saberes, técnicas y prácticas que configuran estilos e identidades culturales y en las formas de organización socio-cultural-productiva de apropiación de la naturaleza.

El diálogo de saberes no produce pues la síntesis e integración de los saberes existentes: enlaza palabras, razones, prácticas, propósitos, significaciones que en sus sintonías y disonancias, sus acuerdos y disensos, van formando un nuevo tejido social. El diálogo de saberes está presente en todo conflicto ambiental que se expresa por intereses contrapuestos en torno a la apropiación social de la naturaleza. Pero trasciende al diálogo interdisciplinario y a la idea de reabsorber el conflicto social generado por la externalización (exterminio) de la naturaleza por la vía de retotalización del saber. El conflicto ambiental no es resoluble (reintegrable en lo Uno y lo Mismo) por medio del conocimiento objetivo de la ciencia ni por su reintegración interdisciplinaria del saber, desplazando la problemática de una gestión científica de la sustentabilidad hacia el campo (abierto) de un conflicto por la reapropiación social de la naturaleza. Es allí donde la interdisciplinariedad se desplaza hacia el diálogo de saberes.

El diálogo de saberes demanda palabras que los articulen en algo más que un postulado o una axiomática, de una racionalidad instaurada en una realidad, para dar coherencia y consistencia a aquello que hoy empieza a manifestarse en el encuentro y enlazamiento de discursividades, de pensamientos, de hablas y de acciones que plantea la relación entre el ser y el saber. Se trata del campo de una política de la diferencia que pone en movimiento una relación del ser y lo real, con lo Otro y con el Infinito.

El diálogo de saberes se produce en un nuevo espacio de relaciones que desborda al campo comunicacional establecido por reglas de racionalidad. Es un encuentro entre 
seres diferenciados a través de discusividades cuyos sentidos trascienden a las relaciones entre las cosas del mundo marcadas por signos que, desde una densidad histórica de significados asignados a la realidad, han sido postuladas, codificadas y afirmadas en las expresiones del lenguaje y en sus estrategias argumentativas sobre un "estado de cosas". El diálogo de saberes está más allá de la positividad del lenguaje que afirma al ser y al pensamiento, que se hace presente en toda enunciación y predicación. El diálogo de saberes convoca también al encuentro a esas sombras de la nada que acompañan a la creatividad que surge de toda denominación de las cosas del mundo, a la emergencia de lo nuevo que emana como fuente del encuentro de saberes: lo irrepresentable, lo inefable, lo insólito, lo inédito; lo que pone en predicamento a todo predicamento que busca instaurar su realidad, y fijar su presencia como presente intemporal. El ser-saber dialoga con lo que aún no es y con lo que nunca adviene al ser, pero que moviliza el surgimiento del pensamiento y la insurgencia de la acción.

El diálogo de saberes se inscribe en una política de la diferencia que trasciende a todo ecologismo que desde su mirada sistémica, está a la espera de la emergencia de una conciencia ecológica prefigurada en el seno de las relaciones ecosistémicas que soportan la vida del planeta. Es esta política de la diferencia la que impide una reabsorción de los diversos seres, saberes e identidades en lo Mismo, en lo Uno, sea esta la unidad de las relaciones que postula la ecología generalizada, la unidad dialéctica de los contrarios, la unidad de la ciencia, el pensamiento único o el cerco hegemónico de la ley del mercado.

El diálogo de saberes no es un diálogo intersubjetivo en la búsqueda de un consenso a través de una racionalidad comunicativa. Más allá de una política de la interculturalidad, se plantea en el campo estratégico del posicionamiento de actores sociales ante la reapropiación social de la naturaleza y la construcción de un futuro sustentable. Ese futuro más allá del conocimiento no es tan sólo obra de la fecundidad del Yo, de un yo que abierto al Otro trasciende el cerco de lo Mismo, del pensamiento único, del cierre de la historia por un logos centralizador y un mercado globalizador. El diálogo de saberes se despliega desde identidades propias que, sin recurso a una esencia, se "reconfiguran" inventando nuevos territorios del ser, que se demarcan del Gran Otro de la globalización económica, como razón de fuerza mayor, para hablar desde nuevos lugares del ser. Desde el arraigo del ser cultural en identidades y sus territorios, se generan saberes ambientales que se encuentran y dialogan en un intercambio de experiencias, resolviendo los conflictos generados por intereses contrapuestos, hibridando las ciencias con los saberes y prácticas tradicionales. Es este diálogo de saberes el que genera el plasma donde forja la posible sustentabilidad.

El diálogo de saberes se plantea como una condición de la democracia en el campo de la sustentabilidad, lo que desborda el campo de una gestión del desarrollo sustentable basado en el conocimiento de la ciencia o el conocimiento experto, para incluir las visiones, saberes e intereses que entran en juego, fuera de la ciencia, en la reapropiación social de la naturaleza. En este sentido, el futuro sustentable no podría asegurarse mediante una racionalidad cognitivoinstrumental. Más bien pone en juego una multiplicidad de racionalidades e intereses, cuya resultante sería un mundo más equitativo, democrático, diverso y sustentable, donde nada está asegura-do de antemano.

Mas si la sustentabilidad está "más allá" de un proceso conducido por el control de la razón (científica, interdisciplinaria), el diálogo de saberes anuncia la transición de un mundo objetivado hacia la resignificción del mundo que subvierte y trasciende a una comunión de valores y una lógica que orientaría el proceso de desarrollo hacia un "futuro común" (la internalización de una conciencia ecológica y de un valor de la supervivencia de la vida), y a la negociación de intereses bajo la lógica del mercado.

La sustentabilidad convoca a una palabra nueva para reconducir la historia. Pero no encuentra el campo labrado y libres las vías de acceso; no sólo por las cargas denotativas del lenguaje que arrastra la realidad presente, sino sobre todo por las estrategias de poder en el saber, que obstaculizan las posibilidades de la sustentabilidad convirtiéndolas en una retórica del desarrollo sostenible, en la afirmación de un presente insustentable.

El diálogo de saberes se establece en la vía de la comprensión del mundo, más que del conocimiento de la realidad, de saberes objetivos sobre procesos objetivados, cosificados, realizados. El conocer margina al sujeto y al sentido; el entendimiento comprende las relaciones entre procesos en el encuentro de las formas diferenciadas de significación del otro, de los otros.

Ciertamente el diálogo de saberes se ofrece como un proceso de comunicación de saberes, de intercambio de experiencias y complementación de conocimientos. Mas no es una metodología para establecer una comunidad de aprendizaje, de la misma manera que el pensamiento de la 
complejidad no es un método para la interdisciplinariedad de las ciencias. El diálogo de saberes no sólo establece un espacio de sinergias y complementariedades entre los saberes existentes sobre el mundo actual y la realidad presente, sino que apunta a la producción (más que la generatividad óntico-epistémica-científica-tecnológica) de nuevas formas de comprensión del mundo que emergen de la dialógica del intercambio de saberes y de la disputa de sentidos en la reapropiación social de la naturaleza y de la cultura.

\section{Diálogo de saberes y racionalidad ambiental}

El conocimiento sólo conoce objetos, aun los objetos del conocimiento. Conoce objetivando el mundo. Entre más lo aprehende, más se desborda sobre lo incognoscible, sobre lo impensable. El saber ambiental es pura externalidad de ese centro, de esa objetividad. El no saber del conocimiento alza su vuelo como águila sobre un abismo, flotando sobre el vacío del pensamiento para detener la caída del ser en la nada. El saber ambiental no aspira a la retotalización del mundo y a la complementariedad del conocimiento por la vía del diálogo de saberes. El saber ambiental se construye como recuperación del ser, apertura del mundo hacia lo posible, liberación del cerco del conocimiento y la jaula de la racionalidad. Es el soplo de vida que renace de la pulverización del conocimiento objetivo, en los intersticios que se abren de sus fracturas y en la diferencia del ser; polvo terrenal que se hace suelo fertilizando una nueva racionalidad, otra manera de pensar el mundo, de vivir en la tierra.

En la categoría de racionalidad ambiental, lo sustantivo es el concepto de ambiente. El ambiente es el saber que emerge en el espacio de externalidad del logocentrismo de las ciencias modernas. La crisis ambiental es generada por el desconocimiento de lo real -la exclusión de la naturaleza, la marginación de la cultura, el exterminio del otro, la anulación de la diferencia-, por la unidad, sistemicidad y homologación de las ciencias. La problemática ambiental es el efecto que produce la racionalidad formal, instrumental y económica como formas de conocimiento y en su voluntad de dominación, control, eficacia y economización del mundo.

Mas el ambiente no es el campo de exterminio de la razón, espacio de exclusividad de lo inconsciente y lo irracional, delirio de una ética divorciadas del juicio racional.
La cuestión ambiental inaugura una nueva racionalidad; es racional porque es pensable (incluyendo el orden de lo no pensado y de lo por pensar); moviliza saberes y acciones sociales para la construcción de sociedades sustentables.

La racionalidad ambiental no es una "ecologi-zación" del pensamiento ni un conjunto de normas e instrumentos para el control de la naturaleza y la sociedad, para una eficaz administración del ambiente. La racionalidad ambiental es una teoría que orienta una praxis a partir de la subversión de los principios que han ordenado y legitimado la racionalidad teórica e instrumental de la modernidad. Es una racionalidad -en sentido weberiano- que articula una racionalidad teórica e instrumental con una racionalidad sustantiva; es una racionalidad que integra el pensamiento, los valores y la acción; es una racionalidad abierta a la diferencia, a la diversidad y pluralidad de racionalidades que definen y dan su especificidad e identidad a la relación de lo material y lo simbólico, de la cultura y la naturaleza (LEFF, 2001a).

La racionalidad ambiental es una razón desconstructora de la racionalidad de la modernidad; es una racionalidad abierta a lo impensable dentro de los códigos de la razón establecida. Es una razón crítica de la racionalidad dominadora -encerrada en sí misma y cegada a la otredad-, para pensar la diferencia y lo que aún no es; es una categoría para construir un real que haga posible la realización de esos fines a los que apuntan esas desgastadas palabras (equidad, democracia, diversidad, sustentabilidad), para devolverles su sentido y su potencialidad.

La apertura al futuro no es un mero reinicio de la génesis del mundo movilizada por la autoorganización de la materia y por las infinitas posibilidades de traer el mundo al ser por la asignación de significados a la realidad mediante la función creadora del signo. El futuro sustentable es una construcción social que emerge de la tensión productiva del encuentro de seres y el diálogo de saberes, que cuestiona el imperio de una racionalidad cosificadora y objetivadora, la mercantilización de la naturaleza y la economización del mundo; la impotencia de la palabra para significar la hiperrealidad que ha generado la racionalidad instrumental y las formas de conocimiento del mundo. El futuro sustentable se debate entre la automatización de procesos en los que se aceleran las intercomunicaciones y la sinapsis de conexiones electrónicas generadoras de realidades virtuales, y la posibilidad de que la historia se reoriente por la vía de la recreación y multiplicación de sentidos -de una vida sentida y con sentido- que supere el 
vertiginoso vértigo de la expulsión hacia la nada del ser por el automatismo autorreflexivo del cálculo y la aceleración de colisiones de objetos fuera de todo significado que rebasan las posibilidades de recuperación del sentido mediante la comunicación de comunidades interactivas guiadas por intereses, ideologías y pasiones comunes.

Allí donde el habla se agota en su capacidad de generar comunión y sentido es donde la racionalidad ambiental aparece como una razón que orienta la sustentabilidad y una ética por la vida fundada en el sentido de la existencia (cultura) y su relación con lo real (naturaleza); donde el sentido aún pueda ser encarnado (embodied) en un serahí, arraigado y territorializado (embedded) en la tierra firme de lo real: una racionalidad capaz de contrarrestar la proyección hacia el vacío de la realización y racionalización, objetivación y fragmentación del mundo conducido por las leyes ciegas del mercado - de un mercado libre de ideas-, donde la palabra y el concepto dejan de "tocar" al mundo, de producir significaciones, disolviéndose en la transparencia de una realidad en el cual ya no hay creación posible.

El punto crucial del futuro sustentable está entre la operatividad de un proceso de generatividad y autoorganización de la materia y el conocimiento (de los mecanismos de la mutación genética y la evolución biológica a los de la innovación tecnológica y la comunicación electrónica en la hiperrealidad virtual, y un devenir como creatividad y poiesis, un llegar a ser del Ser (Heidegger) a través de la palabra y el pensamiento, del sentido y la significancia, de la relación de lo real y lo simbólico.

El diálogo de saberes es el proceso que libera al mundo de la fijación de la realidad en la generalidad de lo uno -en la globalización de ley universal del mercado-, para abrir el horizonte de un más allá; de un porvenir cuyo motor no es la generatividad de la physis sino un campo de posibilidad que se funda en la potencialidad de lo real movilizado por el deseo de ser y la significancia del mundo. La racionalidad ambiental está más allá de la ontología pero no es puro imaginario. El porvenir está iluminado por la responsabilidad hacia el otro que se expresa en la epifanía del rostro y que se vuelve acción a través del diálogo en un fondo de intereses contrapuestos por la apropiación del mundo. En ese contexto, la responsabilidad como habilidad para responder al otro se convierte en el principio de un diálogo de saberes: ...la activación de la responsabilidad (decisión, acto, praxis) siempre tendrá lugar antes y más allá de cualquier determinación teórica o temática (...) Disidencia, diferencia, herejía, resistencia, secreto -tantas experiencias que son paradójicas en el sentido fuerte que Kierkegaard le da a la palabra. De hecho se reduce a vincular el secreto a una responsabilidad que consiste (...) en respon$d e r$, es decir, en contestar al otro, ante el otro y ante la ley. (DERRIDA, 1996, p. 26)

El diálogo de saberes es una relación que más allá de comprender las relaciones ontológicas del mundo, compromete una responsabilidad con el otro; pero no es una pura relación ética, pues la ética que asume la responsabilidad con el otro no destraba la fijación del espíritu totalitario de la realidad globalizada. El diálogo de saberes se inscribe dentro de una política de la diferencia que moviliza actores sociales constituidos por saberes que se enfrentan en procesos de apropiación de la naturaleza. Aquí el saber se ubica en otro lugar que el conocimiento que intenta correlacionar el concepto con la realidad. El saber que constituye al ser es un saber fáctico pero al mismo tiempo es una constelación de sentidos que organizan prácticas culturales y productivas. Es un saber que no renuncia a la razón, pero que la irriga con sensibilidades, sentimientos y sentidos. El diálogo de saberes fertiliza la diversidad cultural; no es solo confluencia, consenso y síntesis de pensamientos y conocimientos, sino una serie sin fin de relaciones de otredad entre seres diferenciados, sin síntesis dialéctica, donde las hibridaciones y confrontaciones de saberes generan nuevos potenciales para afianzar identidades singulares y heterónomas que, en un proceso inverso a la homogeneidad y a la generalidad de la idea universal, fortalece cada autonomía en las sinergias de encuentros con lo otro y lo diferente. Pues, como señala Floriani,

Todos los humanos poseen un marco cognitivo, pero los diferentes humanos poseen marcos diferentes. Los diálogos y contactos entre humanos son, por lo tanto, procesos de constante (y de hecho, infinita) traducción: entre lenguajes y entre marcos cognitivos. (FLORIANI, 2004, apud BAUMAN, 2001). 
El diálogo de saberes no es un mero intercambio simbólico. La significancia del lenguaje destraba la supuesta correspondencia y fijeza entre las palabras y las cosas. Pero no se establece en un divorcio con lo real. El diálogo de saberes es un diálogo entre lo material y lo simbólico, entre cultura y naturaleza. El diálogo de saberes nace en ese momento en que expulsado el lenguaje del paraíso de la unidad, después de Babel, las lenguas se enlazan como lianas con una naturaleza que despliega las ramas de la vida en la exuberante biodiversidad del planeta conducida por la cultura. Es la dispersión que surge de esa explosión originaria del ser y de la identidad en la que la primera palabra del mono gramático toca a la semilla, donde se enlazan los signos de la palabra con los signos de la naturaleza en el erotismo infinito de la relación entre lo real y lo simbólico:

Hanuman: mono / grama del lenguaje, de su dinamismo y de su incesante producción de invenciones fonéticas y semánticas. Ideograma del poeta, señor / servidor de la metamorfosis universal: simio imitador, artista de las repeticiones, es el animal aristotélico que copia del natural pero asimismo es la semilla semántica, la semillabomba enterrada en el subsuelo verbal y que nunca se convertirá en planta que espera su sembrador, sino en la otra, siempre otra. Los frutos sexuales y las flores carnívoras de la alteridad brotan del tallo único de la identidad. (PAZ, 1974, p. 111)

Esta creatividad de la historia fundada en el encuentro con la otredad, la recreación del mundo y la construcción de un futuro, hoy aparece como una quimera más que como una utopía, cuando el terror en la era de la globalización impone la desconfianza hacia el otro, cuando la sociedad homogeneizada en sus formas de ser y pensar ve en su semejante (Der Doppelgänger: Heine) el reflejo fantasmagórico de uno mismo que le reafirma su identidad aterrorizada y fantasmagórica, va-ciada de significado y de sentido.

Y sin embargo, sólo la relación con lo Otro abre la vía para salir de la mismidad ensimismada del yo que se afirma en la presencia y en la empiricidad de la realidad. La otredad es la condición del ser -del ser allí fuera del yo-, pues como especula Paul Auster, "Ser está siempre afuera, nunca dentro del yo mismo" (1990, p. 132). Haciendo resonar el llamado del inconsciente freudiano: "wo es war soll ich werden" y la poética de Baudelaire: "il me semble que je serais toujours bien là où je ne suis pas", Auster afirma: "wherever I am not is the place where I am myself". Este enunciado vendría a problematizar las propuestas heideggeriana y lévinasiana -la primera por pensar el ser como anclaje y fundamento de toda ontología; la otra por pensar todo encuentro con la otredad desde la ipseidad del yo como el lugar desde donde la mismidad puede mirar al otro, migrar hacia lo otro. El ser afuera del yo mismo (self), significa que el ser no se constituye en la afirmación del yo ni desde las determinaciones que le vienen del inconsciente, sino desde una exterioridad del yo mismo, en relación con lo otro. Decir que soy en el lugar en el que no estoy, significa que no soy allí, sino en un lugar allá, afuera en el mundo, fuera de mi mundo. Mi ser no se constituye en una relación interna, sino en una relación con una otredad que no es la del Otro inconsciente o de la condición existencial del ser para la muerte, sino de la externalidad del yo y del ser. Salir al encuentro con lo otro es desandar el camino para llegar a ese lugar donde aún no soy, donde no estoy, del cual aún no hay un saber; donde el saber encarna en el ser; saber que siente y se hace sentido, siguiendo el sendero señalado por Eliot:

Para llegar a donde estás, para ir desde donde no estás, Debes ir por un camino en el que no hay éxtasis.

Para llegar a lo que no sabes

Debes tomar el camino que es el camino de la ignorancia. Para poseer lo que no posees,

Debes ir por el camino de la desposesión.

Para llegar a lo que no eres

Debes ir a través del camino en el cual no eres.

Y lo que no sabes es lo único que sabes

$Y$ lo que tienes es lo que no tienes

Y donde estás es donde no estás. (ELIOT,)

El ser se desborda hacia lo otro antes de poder totalizarse en su interioridad. Pero Steiner nos previene sobre cualquier salida fácil hacia la exterioridad del "ser con", ya sea en una relación ética o en los entramados del lenguaje:

Ser nos sobrepasa con su coerción ciega y dispendiosa. Siempre está "en exceso". Somos llevados ante ello hacia nuestra extinción personal (...) Lévinas en su diálogo continuo con la celebración del ser de Heidegger, argumenta que sólo el altruismo, sólo la resolución de vivir para los otros, puede validar y hacer aceptable el terror 
de la existencia. Debemos trascender el ser para "ser con". Una noble doctrina, pero también una evasión. Ningún motivo de sacrificio, ninguna lucha por reparar, va al corazón de la cuestión. (STEINER, 2001b, p. 40)

El diálogo de saberes fertiliza la existencia humana en el encuentro de seres diferenciados. Su potencial no está en la generación de un consenso de perspectivas que anularía las diferencias a través de una racionalidad comunicativa, de una negociación de intereses, de una síntesis dialéctica o una ética de la responsabilidad y la otredad. El diálogo de saberes es una comunicación entre seres constituidos y diferenciados por sus saberes; en la forja del ser-ahí en el saber que se plasma en el ser cultural que diferencia al ser genérico -ser para la muerte-, en una pléyade de seres culturales constituidos por identidades propias, que acarrean una marca de origen pero al mismo tiempo las reinventan al diferenciarse (resistir y desistir) de la identidad global y el pensamiento único. Ese encuentro entre seres en el diálogo de saberes prende la chispa de la creatividad humana, donde la diversidad cultural se vuelve innovación discursiva, hibridación de racionalidades y sentidos que se despliega ramificando procesos que enlazan diversas vías de significancia entre lo simbólico y lo real, entre el pensamiento y la acción; donde las ramas del saber se sueltan del tronco del conocimiento para convertirse en nuevas raíces y fertilizar nuevos territorios del ser, del saber: producción infinita de sentidos que, entre filiaciones y otredades, abona el suelo de la fertilidad humana.

El diálogo de saberes trasciende así el solipsismo del sujeto y de la razón individual y la ipseidad del yo en su relación con el otro. Es sobre todo el encuentro de identidades colectivas fundadas en autonomías culturales, desde donde se despliega un diálogo intercultural. Es en este sentido y en este contexto que están emergiendo proyectos, estudios y movimientos sociales en los cuales la autonomía cultural aparece como condición del desarrollo sostenible y una sociedad fundada en la convivencia de sujetos autonómicos basados en sus diversidades culturales y en una política de la diferencia. ${ }^{1}$

El diálogo de saberes no se da en una multirreferencialidad con la complejidad de lo real desde un saber de fondo. Por el contrario, el diálogo de saberes produce un saber sin fondo, abierto al infinito por la interacción del ser y el saber con el mundo, donde la relación de lo real con lo simbólico trasciende al significado de la palabra y la cosa y desborda la relación de significación entre el concepto y la realidad. En diálogo de saberes en la diversidad cultural y en el contexto de una política de la diferencia no se da en un saber de fondo porque la comunicación es un intercambio de sentidos, no siempre y no en todo convergentes, entre interlocutores con lenguajes, significancias, intenciones e intereses diferentes; sentidos anclados en un yo (individual) y un nosotros (colectivo) que no se funden en un todos más allá de la condición común "todos los hombres son mortales" como lo afirma el silogismo y lo confirma la experiencia.

No hay saber de fondo en una acción comunicativa que implica un diálogo entre desiguales y diferentes, porque toda comunicación busca un entendimiento y entender es siempre traducir (STEINER, 2001a). Toda palabra pronunciada, todo mensaje emitido, todo sentido compartido, pone

1 El proyecto Latautonomy, financiado por la Unión Europea, es un ejemplo de este intento de implementar nuevos parámetros para establecer una sociedad convivencial, a partir de los presentes procesos de autonomía en sociedades indígenas de América Latina para una "política orientada al desarrollo sostenible y la democratización de un ambiente social". Su objetivo principal es la elaboración de un concepto de autonomía multicultural como una alternativa socioeconómica y un marco político a los Estados nacionales centralizados sobre la base de identidades culturales. Tomando como ejemplo aquellas áreas indígenas de América Latina donde los procesos de autonomía durante las últimas dos décadas han creado una base política y socioeconómica para un desarrollo sostenible, el proyecto busca analizar y evaluar los esfuerzos de los que hacen política tanto en las organizaciones basadas en la comunidad, como en organizaciones gubernamentales y no-gubernamentales, para crear un nuevo marco para el desarrollo de sociedades civiles. Con este fin, el primer objetivo científico del proyecto será la investigación, análisis y evaluación de los conceptos y prácticas de sociedades indígenas en seis áreas principales de América Latina:

- la región de Chiapas, México, y la lucha del movimiento zapatista por la autonomía municipal;

- la Región Autónoma del Atlántico Norte (RAAN) de Nicaragua, donde la vida política y económica de toda una región está regulada por el Estatuto de Autonomía de 1986

- la región Kuna de San Blas, Panamá, primer área donde se ha puesto en práctica la idea de autonomía multicultural, especialmente al nivel de la educación multilingüe; - los pueblos indígenas de Venezuela, donde la nueva constitución de enero de 2000 ha llevado a una discusión amplia adentro y afuera de las comunidades indígenas. - la región de Alto Río Negro, Brasil, que ha sido declarado oficialmente en 1998 como Territorio dos Indios, como resultado de una alianza de 34 diferentes pueblos indígenas;

- la Sierra de Ecuador, donde la Confederación Nacional de Organizaciones Indígenas del Ecuador (CONAIE) ha conseguido importantes espacios autonómicos con un alto grado de autonomía territorial luchando en el presente por la constitución de un estado plurinacional multiétnico y pluricultural;

- la región del Chapare, Bolivia, donde el movimiento de los Cocaleros de base indígena multiétnica está luchando por el control de los municipios dentro del acuerdo de la Ley de Participación Popular. 
en movimiento un desciframiento y comprensión desde el lugar de otro, que no disuelve su diferencia en un entendimiento común; lo que disolvería la significancia misma del lenguaje y del ser en el que anida en un significado fijado entre signo y referente. Como un juego intergaláctico, el diálogo de saberes es el encuentro entre soles se iluminan, chocan y se dispersan desde diferentes trayectorias, cambiando luces y colores, transformando la materia por un fuego que no consume la autonomía de los astros que en su interacción funden sus cuerpos celestiales para generar nuevas estrellas que deambulan desorbitadas en la entropía del firmamento que no está sellado por la palabra divina ni por la ley universal; espacio exterior en espera de la palabra humana.

La relación entre las palabras y las cosas, entre el concepto y lo real no alcanzan a completar un mundo, ni siquiera entre los hablantes de una misma lengua y en el seno de una cultura. Siempre hay algo de lo real que se anuncia en el lenguaje, aunque no siempre se enuncia por la palabra. La realidad se produce por el lenguaje. Hay un algo que se genera por la significancia del lenguaje -que no es ni la designación de la realidad ya dada por la palabra ni un efecto de conocimiento- que en tanto no adviene a la presencia, es invisible, impensable e inefable. Ese algo por venir que nace de la relación de significancia entre lo real y lo simbólico, es activado por el diálogo de saberes.

El diálogo de saberes abre los sentidos que se cierran y se agotan en la designación del mundo por la palabra, donde la existencia queda consignada en un designio, en una deuda-significado-culpa del ser con la realidad forjada por el signo y el código, ante la cual el sujeto resignado, sometido al poder de la palabra que fija lo real en una realidad, deja de aletear y sobrevolar el mundo en búsqueda de nuevos significados.

El diálogo de saberes emancipa el poder de la palabra desde la tensión de otros lenguajes y otras miradas; desde la otredad del ser y del saber. Tensión de seres-saberes que está más allá de la dialógica y la dialéctica de sentidos preestablecidos; que enfrenta a seres constituidos por saberes encarnados en sentimientos, sensualidades y sentidos que no se colman y saturan en la totalidad de lo ya sido, lo ya pensado, lo ya asignado por la palabra. Estos seres-saberes se cargan de energía, generan sinergias en su apertura y tensión con la otredad, con el Otro, con lo otro, con la nada y con el no saber; con la diferencia y diversidad de lo existente; con el advenimiento de la existencia en su relación con lo sido, con lo conocido, y con el porvenir; con lo por pensar y con lo que aún no es. Este diálogo prepara el campo para una fertilización infinita de sentidos por la palabra, da lugar a la palabra nueva, pues

La fruta de la pasada estación fue comida Y la bestia bien alimentada pateará el plato vacío Pues las palabras del año pasado pertenecen al lenguaje del año pasado

Y las palabras del año siguiente esperan una nueva voz. (ELIOT, [19-])

El futuro sustentable será el fruto de ese tiempo nuevo, donde la palabra pueda bañar con su frescura al ser secuestrado y a lo real paralizado por la palabra envejecida, por el arma teórica que ha conquistado al ser y lo ha encarcelado en su realidad. Pues desde la meta-física, el pensamiento ha cosificado al mundo, encer-rándolo en sus conceptos y categorías (ser, naturaleza, ente, cosa, idea, mente, cuerpo). En todo este revuelo de palabras lanzadas al viento desde la antigua Babel, la significancia del mundo se reactiva desde la potencia del habla en el movimiento del diálogo de saberes (todo lo contrario al extraviado deseo de construir diccionarios y glosarios que fijen el sentido de los conceptos para lograr un consenso y una comprensión de la complejidad ambiental sobre un fondo común de saber). La palabra es como el amor gitano: un enfant de Boheme qui n'a jamais connu de loi.

Es así como la ética se reencuentra con la ontología y con la gnoseología en la relación de lo real, lo imaginario y lo simbólico, en el acto de pensar y de sentir, de ser en el mundo y de construir un mundo desde un ser diverso arraigado en su cultura, en sus formas de significar sus mundos de vida, desde una ética de la otredad y una política de la diferencia.

La racionalidad ambiental en la que se inscribe el diálogo de saberes conduce hacia un nuevo concepto de lo social -de las relaciones sociales, del tejido social-, donde se inscriben los procesos de sociabilidad del ser y del saber. Contra la idea de que la sociabilidad provendría de la autonomía del sujeto y su capacidad como hablante, Vigotsky comprendió que

...todas las funciones psíquicas superiores surgen de una colaboración social (que) en el lenguaje interior surge de la diferenciación de la función originariamente social del lenguaje (de) la progresiva individualización que 
se produce sobre la base de su esencia social. (MARINA, 1998, p. 86)

La constitución originaria del yo mismo provendría de su esencia social. La otredad encontraría su fundamento en "lo humano" sobre la base de su "esencia social". La lengua y la facultad del lenguaje no son propiedades individuales, sino que surgen de la sociabilidad originaria del ser humano. Lo que

...supone admitir que la mente "individual" es en realidad social, en su génesis y su funcionamiento. El lenguaje interior se origina por la introyección del habla comunicativa, y de ella retiene sus propiedades. Los signos, en su carácter externo, son instrumentos objetivos de la relación con otros. Al volverse interiores se convierten en instrumentos internos y subjetivos de la relación con uno mismo. (MARINA, 1998, p. 87)

Lo anterior abre la pregunta sobre esa "esencia social", una sociabilidad originaria del ser humano anterior al lenguaje y al habla comunicativa, donde emerge y se configura el yo mismo que sale al encuentro con el otro. Mas, ¿Qué relaciones constituyen lo social, si es que este tejido no está hecho primordialmente de lenguaje? ¿Dónde encontramos la esencia social cuando esta se fuga de las relaciones de producción, de la significación de la lengua, y del orden de la cultura? Tal vez habrá que rastrearla en el orden del poder, de las estrategias de poder en el saber y su encarnación en el ser.

No podemos hoy concebir la generatividad de lo humano y lo social en términos del paradigma del progreso fundado en el desarrollo de las fuerzas productivas, de esa razón dialéctica puesta al servicio de un materialismo histórico fundado en su base económica. No solo por el fracaso histórico del socialismo real, sino porque la crisis ambiental marca el límite de la racionalidad económica e instrumental que orientó los fines de la modernidad. No es la objetividad de la dialéctica entre fuerzas productivas y relaciones sociales de producción lo que abre la historia a través de sus cambios revolucionarios. Su objetividad queda atrapada en el sistema de representación desde el cual la conciencia no alcanza a desalienarse de la cosificción económica del mundo. La salida hacia un mundo sustentable y con sentido existencial está en la exterioridad de ese mundo cosificado y su apertura hacia el ser. En este sentido, Lévinas afirma:
La existencia del hombre permanece fenomenal en tanto que sigue siendo interioridad. El lenguaje por el cual un ser existe para otro, es su única posibilidad de existir una existencia que es más que su existencia interior (...) Entre la subjetividad cerrada en su interioridad y la subjetividad mal entendida en la historia, está la asistencia de la subjetividad que habla. (Ibid, p. 200) Con la exterioridad, que no es la de las cosas, desaparece el simbolismo y comienza el orden del ser (...) Lo que falta a la existencia interior no es un ser superlativo, que prolongue y amplifique los equívocos de la interioridad y de su simbolismo, sino un orden en el que todos los simbolismos se descifran por los seres que se presentan absolutamente: que se expresan. (LÉVINAS, 1997, p. 195)

El ser no se devela a través de una esencia, de una verdad oculta pero inmanente. El ser se expresa a través de un saber, que no es un código interno, sino un tejido de relación entre lo interno y lo externo, entre lo material y lo simbólico, entre el objeto y su ambiente, entre el presente y el devenir, entre yo y el otro. El ser se constituye en relación con un saber y se expresa por un discurso ante otro discurso -como el sentido que no proviene de la relación unívoca del signo y el significado de la cosa, sino del enlazamiento de un significante con otros significantes en un tejido discursivo. El diálogo de saberes es un diálogo de seres ante una exterioridad. Abre lo que el signo cierra al designar al ser como un ente, como una cosa. Pone en juego nuevamente la palabra viva, el significante abierto ante otro significante:

El ser, la cosa en sí, no es, con relación al fenómeno, lo oculto. Su presencia se presenta en su palabra. Poner la cosa en sí como oculta, implicaría suponer que ella es al fenómeno lo que el fenómeno es a la apariencia. La verdad del develamiento es, a lo sumo, la verdad del fenómeno oculto bajo las apariencias. La verdad de la cosa en sí no se devela. La cosa en sí se expresa. La expresión manifiesta la presencia del ser, no corriendo simplemente el velo del fenómeno. Es, de suyo, presencia de un rostro y a partir de aquí, llamada y enseñanza, entrada en relación conmigo, relación ética. Además, la expresión no manifiesta la presencia del ser al remontar del signo al significado. Presenta el significante. El significante, el que dona el signo, no es significado. Es necesario haber estado en sociedad de significantes para que el signo pueda aparecer como signo. El significante debe pues presentarse 
ante todo signo, por sí mismo: presentar un rostro. La palabra (...) desbloquea lo que todo signo cierra en el momento mismo en que abre el paso que conduce al significado, haciendo asistir al significante a esta manifestación del significado. Esta asistencia mide la excedencia del lenguaje hablado sobre el lenguaje escrito vuelto signo (...) El lenguaje no agrupa los símbolos en sistemas, descifra los símbolos. Pero en la medida que esta significación original del Otro ya ha tenido lugar, en la medida que un ente se ha presentado y se ha auxiliado, los signos distintos a los signos verbales pueden servir de lenguaje. (Lévinas, p. 199)

Pero no se trataría de salvar al lenguaje de sus desviaciones en toda denotación y connotación que desde la formación social establece y cristaliza significados en los imaginarios sociales, en la referencia del signo con lo real, del discurso con la realidad. El nuevo comienzo al que apunta la sustentabilidad no pretende un retorno al estado del lenguaje anterior a Babel, al germen del pensamiento único y de la idea universal, para que el significante pueda generar nuevos sentidos de lo real. El diálogo de saberes se inicia desde seres diferenciados habitados por saberes: saberes que se han constituido en relación con mitos, ritos, prácticas, ideologías y paradigmas de conocimiento.

El diálogo de saberes se establece en el campo de estrategias de poder en el saber: las que se entretejen en cada constelación de saberes; las que se desarrollan en relación con el saber dominante para reorganizar los mundos de vida desde la resistencia a la globalización económica, a la colonización del saber, a la integración cultural. El diálogo de saberes es un campo de confrontación de racionalidades y de hibridación de saberes que arraigan en identidades culturales y en prácticas de uso de la naturaleza. Lo social es anterior y está más allá de toda relación denotativa entre la palabra y la cosa, del signo y el significado, en el sentido de que ningún lenguaje logra abstraerse de las significaciones sociales (culturales) insertas en estrategias de poder por la apropiación del mundo. Más allá de los juegos de lenguaje posibles en la producción del sentido de lo real, el diálogo de saberes se inscribe en un proceso de resignificación y reapropiación cultural de la naturaleza.

El diálogo de saberes, más allá de toda estrategia comunicativa, se establece en este campo del poder en el saber, instaurado en el discurso de la sustentabilidad, donde ningún término es neutro; donde incluso las nociones de territorio, autonomía, cultura y naturaleza son resignificados en este proceso de renovación/apropiación. Es desde la disputa de los sentidos de la sustentabilidad que emerge en lo social una creatividad del lenguaje puesta en juego por el diálogo de saberes, que rompe el cerco de racionalidad impuesta sobre el mundo actual (LEFF, 2001b).

El diálogo de saberes da la mano y abraza a los saberes subyugados, sobre todo con aquellos que dieron sustento a las culturas tradicionales y que hoy resignifican sus identidades y se posicionan en un diálogo y resistencia con la cultura dominante que impone su saber supremo. El diálogo de saberes es un diálogo con interlocutores que han perdido la memoria y la palabra, cuyos saberes tradicionales han sido sepultados por la modernidad impuesta. El diálogo se convierte en indagación, exégesis y hermeneusis de textos borrados; es una terapéutica política para devolver el habla y el sentido de lenguajes cuyo flujo ha sido bloqueado. Es la recuperación de esas "lenguas que una vez fueron de fuego, pero que han sido obliteradas en mudas cenizas" (STEINER, 2001b, p. 203).

No es necesario remitirse a la poesía para cuestionar el propósito representativo del lenguaje. La acción comunicativa desplegada para establecer consensos en torno a una visión y una política del desarrollo sostenible no es producto de la creatividad del lenguaje ni del diálogo racional. El consenso es movilizado por procesos comunicacionales que responden a estrategias de poder que trabajan en el tejido mismo del discurso y de la política, donde los conceptos, los términos y los instrumentos de la gestión del desarrollo sostenible son organizados (innovados, negociados, aplicados) por la lógica del poder de la racionalidad dominadora y no por una racionalidad dialógica crítica. El consenso se sostiene en un discurso automático que se difunde por contagio y mimetismo y no por una respuesta racional de interlocutores heterónomos. Los términos se establecen por la fuerza del uso y la convención sin dar cuenta de la razón teórica del discurso o de la razón práctica que orienta el sentido de las acciones.

La formación de una racionalidad ambiental es un proceso de renovación del mundo, de descontrucción de los fundamentos de la civilización occidental y las falacias de la globalización económica. El diálogo de saberes apunta hacia un renacimiento que no surgirá de la palabra maestra de un dios, sino del encuentro de los seres ahí que habitan el mundo desde sus culturas y sus condiciones existenciales. El diálogo de saberes no es la introyección de los principios preestablecidos de un "futuro común" sino el encuentro del que nace el sentido colectivo, desde sus diversidades y dife- 
rencias, sus consensos y disensos, de sus condiciones ecológicas y culturales de existencia.

En otro lugar que el de la creación filosófica, teórica y poética que extiende sus alas y se hace mundo, del diálogo de saberes nace lo nuevo en el encuentro con la otredad, la diversidad y la diferencia; sin jerarquías, desde el derecho humano a hacerse un lugar en el mundo y a ser con los demás. Condición de dignidad de la existencia humana que hoy reclama su derecho de reapropiación de la naturaleza a través del habla y la palabra.

\section{REFERÊNCIAS}

AUSTER, P. The Invention of Solitude. The Book of Memory. New York: Penguin Books, 1988.

. The New York Trilogy. New York: Penguin Books, 1990.

. Desapariciones. Valencia: Pre-textos, 1996. (prólogo de Jordi Doce)

BAUMAN, Z. En busca de la política. México: Fondo de Cultura Económica, 2001.

DERRIDA, J. The Gift of Death. Chicago: The University of Chicago Press, 1996.

Adiós a Emmanuel Lévinas. Palabra de acogida. Madrid: Trotta, 1998.

ELIOT, T. S. The Complete Poems and Plays (1909-1950). New York, Harcourt Brace \& Company, [19-].

FLORIANI, D. Conhecimento, meio ambiente e globalização. No prelo.

HABERMAS, J. Teoría de la acción comunicativa I. Racionalidad de la acción y racionalización social. Buenos Aires: Taurus, 1989.

. Teoría de la Acción Comunicativa II. Crítica de la razón funcionalista. Buenos Aires: Taurus, 1990.
LEFF, E. Epistemología ambiental. São Paulo: Cortez, 2001a. . Saber ambiental. Racionalidade, sustentabilidade, complexidade, poder. Petrópolis: Vozes, 2001b.

LEFF, E. Pensar a complexidade ambiental. In: LEFF, E. (Coord.). A complexidade ambiental. São Paulo: Cortez, 2003a.

LEFF, E. La ecología política en América Latina: un campo en construcción. Polis: Revista de la Universidad Bolivariana, v. 2, n. 5, p. 125-145, 2003 b.

LÉVINAS, E. Totalidad e infinito. Ensayo sobre la exterioridad. 4. ed. Salamanca: Sígueme, 1977/1997.

El tiempo y el outro. Barcelona: Paidós, 1993.

La huella del outro. México: Taurus, 2000.

MARINA, J. A. La selva del lenguaje. Barcelona: Anagrama, 1998.

PAZ, O. El mono gramático. Barcelona: Seix Barral, 1974.

STEINER, G. Después de Babel. 3. ed. México: Fondo de Cultura Económica, 2001a.

. Grammars of creativity. New Haven: Yale University Press, 2001b. 